\title{
Anomalous Shear Wave Attenuation in the Shallow Crust Beneath the Coso Volcanic Region, California
}

\author{
Chris Sanders, ${ }^{1}$ Phyllis Ho-liu, David RINN, ${ }^{2}$ AND HIROo KaNAMORI \\ Seismological Laboratory, California Institute of Technology, Pasadena
}

\begin{abstract}
We use seismograms of local earthquakes to image relative shear wave anenuation structure in the shallow crust beneath the region containing the Coso volcanic-geothermal area of eastern California. $S V$ and $P$ wave amplitudes were measured from vertical component seismograms of earthquakes that occurred in the Cososouthem Sierra Nevada region from July 1983 to August 1985 . Seismograms of 16 small earthquakes show SV amplitudes which are greatly diminished at some azimuths and takeoff angles, indicating strong lateral variations in $S$ wave attenuation in the area. Three-dimensional images of the relative $S$ wave attenuation structure are obtained from forward modeling and a back projection inversion of the amplitude data. The results indicate regions within a 20 by 30 by $10 \mathrm{~km}$ volume of the shallow crust (one shallower than $5 \mathrm{~km}$ ) that severely attenuate $S V$ waves passing through them. These anomalies lie beneath the Indian Wells Valley, $30 \mathrm{~km}$ south of the Coso volcanic field, and are coincident with the epicentral locations of recent earthquake swarms. No anomalous attenuation is seen beneath the Coso volcanic field above about $5 \mathrm{~km}$ depth. Geologic relations and the coincidence of anomalously slow $P$ wave velocities suggest that the attenuation anomalies may be related to magmatism along the eastem Sierra front.
\end{abstract}

\section{INTRODUCTION}

Anomalously low $S$ wave amplitudes have been reported worldwide in regions of young volcanism, and to varying degrees of precision these data have been used to determine the locations of zones of high $S$ wave attenuation (presumably molten rock) in the crust and upper mantle (Kamchatka, USSR: Gorshkov [1956], Fedotov and Faberov [1966]; Mount Katmai, Alaska: Kubota and Berg [1967], Matumoto [1971]; Iceland: Einarsson [1978]; New Zealand: Latter [1981]; Long Valley, California: Ryall and Ryall [1981], Sanders [1984]; Imperial Valley, California: Ho-Liu et al. [1986]). These studies used $S$ wave amplitude data from seismograms of local and/or regional earthquakes recorded on local seismic arrays and employed back projection in order to map the position of $S$ wave attenuation anomalies in the regions. The success of these studies, especially those in Long Valley caldera in eastern California, encouraged us to use the southern Califomia seismic array for $S$ wave attenuation studies of volcanic-geothermal areas that lie within the array. In the study reported here, the shallow crust beneath the region containing the Coso volcanic field of eastern California is investigated for relative $S$ wave attenuation structure.

The Coso volcanic field is located near the southern end of the Sierra Nevada along its eastern escarpment (Figures 1 and 2). The geothermal potential at Coso has prompted investigations of the geological and geophysical nature of the young volcanic field. Geological investigations [Duffield et al., 1980; Bacon et al., 1980, 1981] have shown that basaltic volcanism began at Coso about 3.6 Ma contemporaneous with the inception of extensional faulting and the formation of the Coso Range. To date about $35 \mathrm{~km}^{3}$ of basalt to rhyolite lavas have erupted from vents in the range, with the most recent volcanic

\footnotetext{
${ }^{1}$ Now at U.S. Geological Survey, Menlo Park, California.

${ }^{2}$ Now in Westfield, New Jersey.
}

Copyright 1988 by the American Geophysical Union.

Paper number 6B6200.

0148-0227/88/006B-6200\$05.00 eruption (basalt; $40 \mathrm{ka}$ ) located at the southern end of the range (the northem end of Indian Wells Valley; Figure 2). The limited geographic distribution and relative volumes of the rhyolite extrusions suggest a relatively small silicic magma reservoir located beneath the central part of the field [Bacon et al., 1980; Duffield et al., 1980]. Basalt vents are more widespread and peripheral to the rhyolite vents suggesting a more extensive, deeper mafic magma reservoir [Duffield et al., 1980]. The recency of rhyolite and basalt eruptions, the constant long-term rates of erupted material (past $0.5 \mathrm{Ma}$ ), and the apparent increase in the average volume rate of eruption of phenocrystpoor, high-silica rhyolite suggest the existence of a still evolving magmatic field [Bacon et al., 1980, 1981; Bacon, 1982].

Geophysical studies (teleseismic $P$ wave velocity, Reasenberg et al. [1980]; teleseismic $P$ wave attenuation, Young and Ward [1980]; gravity, Plouff and Isherwood [1980]; heat flow, Combs [1980]) indicate that a large magma reservoir is not present above $10 \mathrm{~km}$ depth beneath the Coso volcanic field, and local earthquakes studies (local seismicity, Walter and Weaver [1980]; structure and hypocenter inversion, Pavlis and Booker [1983]) further suggest that smaller-scale structures that significantly affect $P$ wave velocities are not present. These studies were limited in areal extent, however, and the existence of magmatic structures outside of the Coso Range was not ruled out. Also smaller-scale structures beneath Coso that affect the seismic wave attenuation more than the velocity were not studied. In this study, we investigate these last two possibilities using records of local earthquakes.

Fortunately, the Coso-southern Sierra Nevada area has thousands of small earthquakes each year, and the California Institute of Technology-U.S. Geological Survey (CIT-USGS) southern California seismic array is unusually dense in this area and spans a large region. Thus, we were able to obtain a data set of amplitudes of seismic phases that had traveled through the local crust along many different azimuths and with varying takeoff angles. The rays traverse an area much greater than that previously studied. These seismograms record short-period seismic waves which should be sensitive to structures a few kilometers in diameter.

In this study, first we examine visually vertical component 


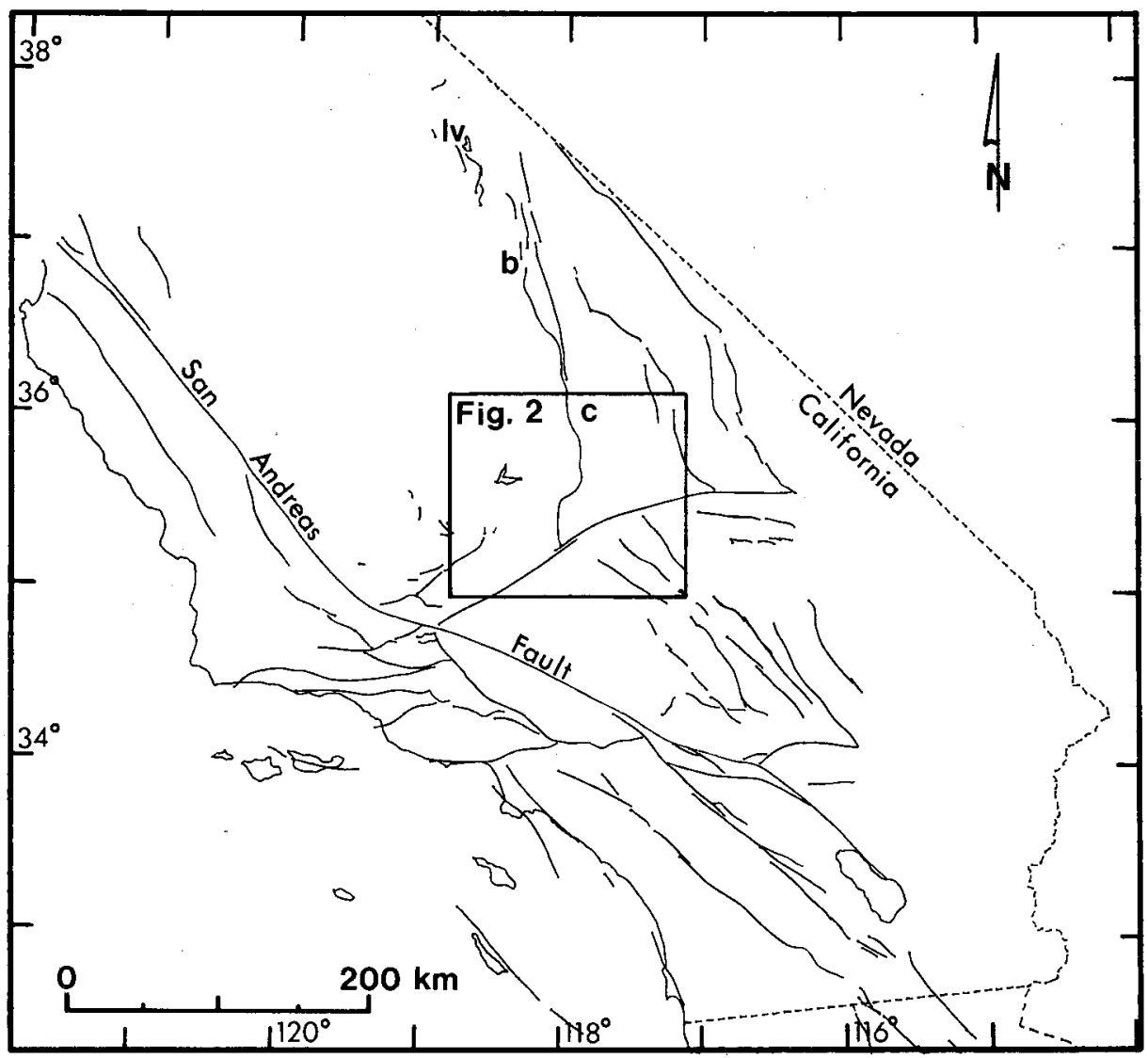

Fig. 1. Map of southern California showing major faults and the location of the Coso study area. Here lv denotes Long Valley; b, Big Pine; c, Coso.

seismograms for relative $S V$ and $P$ wave amplitudes. The relative amplitude determinations which we use in this study are qualitative; however, the attenuation effects on the $S V$ waves are so great that qualitative analysis is a useful method. We later measure the $S V$ to $P$ wave amplitude ratios and find that the visual and quantitative determinations are very consistent. Next, we back project the qualitative amplitude data graphically to map the gross $S V$ wave attenuation structure. Also we invert the data using a tomographic back projection scheme and compare the results with the forward model. We then compare the inversion results with a tomographic back projection inversion for $P$ wave velocity structure by Walck and Clayton [1987]. Finally, we discuss the relation of the $S V$ wave attenuation structure to the local seismicity and geology.

\section{SEISMOGRAM ANALYSIS}

The techniques employed in this analysis are relatively simple. The vertical component seismograph network operating in the area (CIT-USGS southem California array) records seismic waves from small earthquakes in the Coso-southern Sierra Nevada region. The resulting seismograms are routinely analyzed for first arrival times by CUSP (CIT-USGS seismic processor), and earthquake hypocenters are computed. These data are stored on magnetic tape and paper records at the Seismological Laboratory of the California Institute of Technology. We scanned earthquake epicenter maps and hypocenter lists and chose more than 20 earthquakes for detailed analysis. These were systematically selected based on magnitude (the earthquakes are recorded at most of the local stations and the signals are not clipped), epicentral location (maximize azimuthal coverage), depth (maximize depth distribution), and location quality. We analyzed several earthquakes with similar hypocentral locations, and the seismograms were nearly identical. This indicates the consistency of our data, and that redundant data will not improve the results. A few of the earthquakes were not used, because their depths could not be constrained confidently. Our final data set consisted of seismograms from 16 earthquakes (Figure 2, Table 1). We could have analyzed many other earthquakes in addition to these (there were 1172 earthquakes with $M$ 1.6 to 2.3 located in this region in the time period July 1983 to August 1985); however we concentrated on obtaining maximum azimuthal and depth coverage from a small number of wellrecorded earthquakes. More detailed results possibly could be obtained using additional earthquakes.

Each earthquake studied was recorded at dozens of stations of the CIT-USGS southern California seismic array, but we limited our detailed analysis to those records corresponding to travel paths through the area of interest and to stations whose first arrival was $P_{g}$ (assuming a Coso velocity model, Table 2; Figure 2). This amounted to 10 to 30 seismograms (average 20) per event, for a total of 329 rays through the area. The seismograms were examined visually for $P$ and $S V$ wave amplitudes, and each was given a qualitative attenuation number $(A N)$ corresponding to the relative $S V$ to $P$ wave amplitude ratio. Most of the seismograms have normal appearing $S V$ waves ( $A N$ $0)$ ( $S V$ wave amplitude approximately greater than or equal to the $P$ wave amplitude), while some appear slightly attenuated $(A N$ 1) ( $S V$ wave amplitude somewhat smaller than the $P$ wave amplitude) or moderately attenuated $(A N 2)$ ( $S V$ wave amplitude 


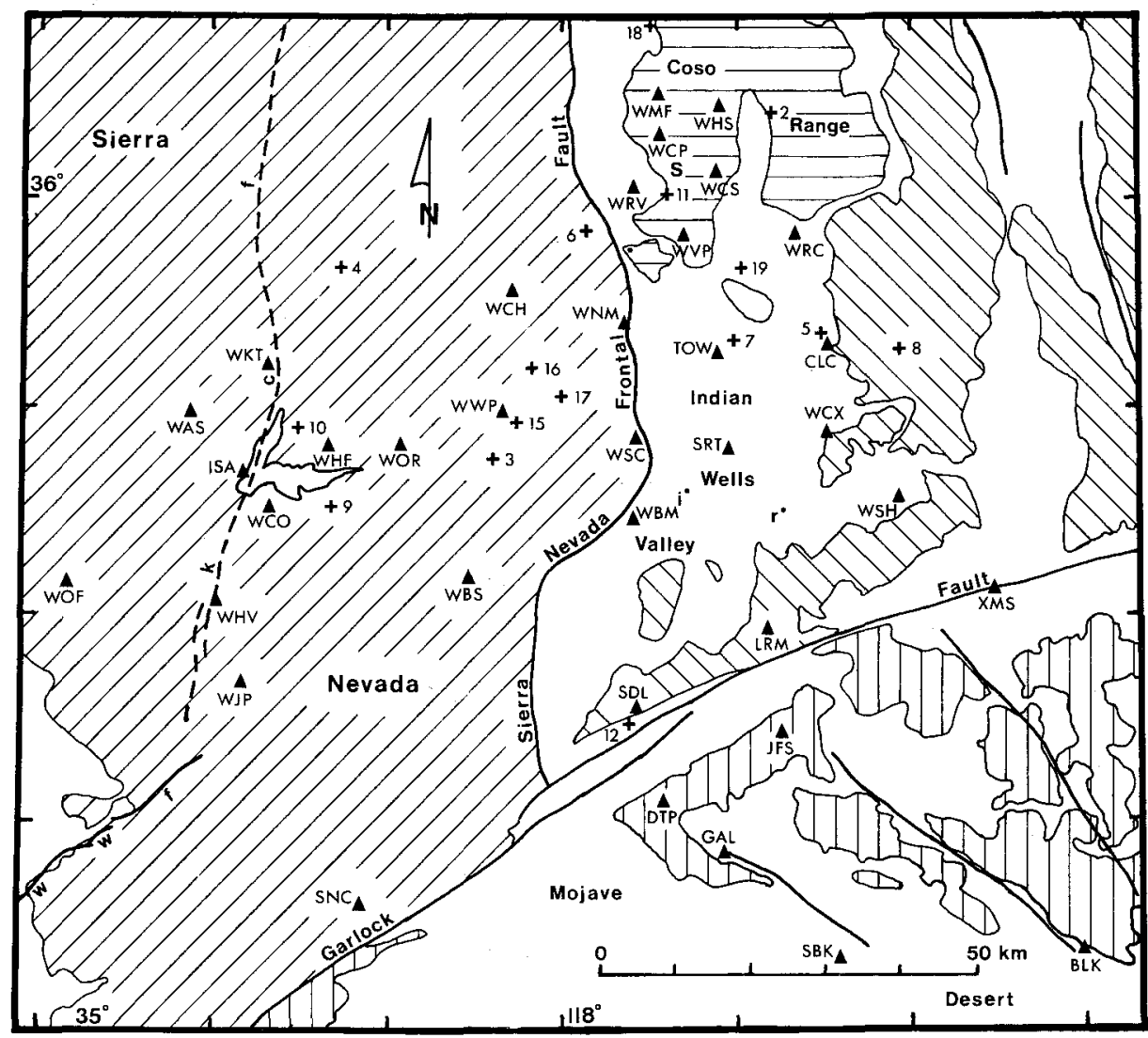

Fig. 2. Tectonic map of the Coso-southem Sierra Nevada region. Major faults are labeled and bedrock outcrops in the crustal blocks are indicated by hatching. The locations of earthquakes and stations used in this study are plotted (Table 1). S, Sugarloaf Mountain (in the Coso volcanic field); i, Inyokem; r, Ridgecrest; wwf, White Wolf fault; kcf, Kem Canyon fault.

much smaller than the $P$ wave amplitude), and a few are very attenuated (AN 3) ( $S V$ wave arrival nearly indistinguishable from the coda). Examples of these qualitative ratings are shown in seismograms from two earthquakes in Figure 3 . Figure $3 a$ shows the epicenters of earthquakes 3 and 8 and the locations of some stations from which seismograms were obtained. In Figure $3 b$ seismograms from earthquake 8 are displayed in order of increasing azimuth, and in Figure $3 c$ three seismograms from earthquake 3 are displayed in order of decreasing takeoff angle. Figures $3 b$ and $3 a$ illustrate that attenuated ray paths from earthquake 8 occur within a small azimuthal range and are bounded by normal ray paths at other azimuths, and Figures $3 c$ and $3 a$ show that the attenuated ray path from earthquake 3 is bounded by normal ray paths at greater and lesser takeoff angles but along a similar azimuth. These seismograms indicate that $S V$ waves are attenuated when the rays travel through a localized region of the crust in this area.

Figure 4 shows the entire data set for this study. Each earthquake is plotted in a separate frame, with the surface projection of the ray paths plotted with line types indicating the qualitative attenuation number. Each epicenter is marked with a cross and the seismic stations with squares. By combining the ray paths and noting the geometry of anomalous and normal rays we are able to determine the relative $S V$ wave attenuation structure of the shallow crust in this area.

Since the qualitative attenuation numbers (amplitude ratios) were obtained by visual inspection (subjective) a more objective assessment of the relative $S V$ wave amplitudes was made by measuring on each record the maximum peak-to-peak $P$ and $S V$ wave amplitudes (within about one-half second of their expected arrival times) (Table 3). The approximate expected $S V$ wave arrival times for each earthquake were found by measuring the $S-P$ time on a seismogram with a sharp $S V$ wave arrival and then extrapolating to get the $S-P$ times at other stations with similar azimuth and $\Delta$. We feel that this method of determining the approximate $S V$ wave arrival is reasonable, since $S V$ wave travel times computed from $P$ wave velocity models can be misleading. The short extrapolation distances should produce small errors. Table 4 shows the relation between the qualitative attenuation numbers and the measured $S V$ wave/ $P$ wave amplitude ratios $\left(A_{S} / A_{P}\right)$. The very attenuated $S V$ waves $(A N 3)$ have average $A_{S} / A_{P}$ of $0.33 \pm 0.08$ (range $0.17-0.50$ ), whereas the moderately attenuated $S V$ waves ( $A N 2$ ) have average $A_{S} / A_{P}$ of $0.52 \pm 0.12$ (range $0.36-0.71$ ). The slightly attenuated $S V$ waves ( $A N 1$ ) have $A_{S} / A_{P}$ of $0.72 \pm 0.16$ (range $0.48-1.23$ ), and the normal seismograms ( $A N 0$ ) have average $A_{S} / A_{P}$ of 2.11 (range 0.63-16.50).

The $A_{S} / A_{P}$ measurements indicate a clear difference in the relative $S V$ wave amplitudes between the $A N 0$ and $A N 3$ seismograms. The $A N 2$ and $A N 0 A_{S} / A_{P}$ measurements overlap minimally, with four $A N 0$ measurements (1.6\%) in the $A N 2$ range. Overall, the $A_{S} / A_{P}$ measurements indicate an essential distinction between the anomalous ( $A N 3, A N 2$ ) and normal $(A N 0)$ seismograms. The $A N 1$ seismograms are ambiguous and are given little consideration. Thus, we will use only the qualitative $A N 0, A N 2$, and $A N 3$ data to image the relative attenuation structure, similar to Sanders' [1984] study of Long Valley. The quantitative $A_{S} / A_{P}$ data are being used in a separate study with nearly identical results (P. Ho-Liu et al., manuscript submitted to J. Geophys. Res., 1986). 
TABLE 1. Locations of Earthquakes

\begin{tabular}{|c|c|c|c|c|c|c|c|}
\hline Event & Date & $\begin{array}{l}\text { Time, } \\
\text { UT }\end{array}$ & $\begin{array}{l}\text { Latitude, } \\
\operatorname{deg} N\end{array}$ & $\begin{array}{l}\text { Longitude, } \\
\operatorname{deg~W}\end{array}$ & $\begin{array}{l}\text { Depth, } \\
\text { km }\end{array}$ & $M_{L}$ & $\begin{array}{l}\text { Velocity } \\
\text { Model }\end{array}$ \\
\hline 2 & Oct. 30,1983 & 1352 & $36^{\circ} 06.89^{\prime}$ & $117^{\circ} 40.35^{\prime}$ & 3.2 & 2.2 & Coso \\
\hline 3 & Feb. 24,1984 & 1343 & $35^{\circ} 41.11^{\circ}$ & $118^{\circ} 06.02^{\prime}$ & 10.5 & 1.6 & Sierra \\
\hline 4 & Feb. 08,1984 & 1156 & $35^{\circ} 55.10^{\prime}$ & $118^{\circ} 19.27^{\prime}$ & 5.5 & 2.2 & Sierra \\
\hline 5 & Jan. 09, 1984 & 1518 & $35^{\circ} 49.87^{\prime}$ & $117^{\circ} 36.29^{\prime}$ & 7.5 & 1.7 & Coso \\
\hline 6 & $\begin{array}{l}\text { Jan. } 27,1984 \\
\text { Feb. } 07,1984\end{array}$ & $\begin{array}{l}0119 \\
0746^{*}\end{array}$ & $35^{\circ} 57.44^{\prime}$ & $117^{\circ} 57.93^{\prime}$ & 9.8 & 2.3 & Coso \\
\hline 7 & Jan. 20,1984 & 0118 & $35^{\circ} 49.34^{\prime}$ & $117^{\circ} 44.64^{\prime}$ & 6.8 & 2.2 & Coso \\
\hline 8 & Oct. 06,1983 & 0720 & $35^{\circ} 48.72^{\prime}$ & $117^{\circ} 29.72^{\prime}$ & 6.5 & 1.2 & Coso \\
\hline 9 & Feb. 02, 1984 & 0824 & $35^{\circ} 37.75^{\prime}$ & $118^{\circ} 20.48^{\prime}$ & 13.6 & 1.9 & Sierra \\
\hline 10 & July 24,1983 & 2046 & $35^{\circ} 43.48^{\prime}$ & $118^{\circ} 24.46^{\circ}$ & 12.0 & 1.7 & Sierra \\
\hline 11 & July 31,1983 & 1608 & $35^{\circ} 59.04^{\prime}$ & $117^{\circ} 50.91^{\prime}$ & 7.4 & 2.0 & Coso \\
\hline 12 & Apr. 06, 1984 & 0906 & $35^{\circ} 21.62^{\prime}$ & $117^{\circ} 54.30^{\prime}$ & 10.2 & 1.3 & Mojave \\
\hline 15 & Sep. 07,1983 & 2225 & $35^{\circ} 43.07^{\prime}$ & $118^{\circ} 03.63^{\prime}$ & 7.0 & 1.6 & Sierra \\
\hline 16 & Apr. 11, 1984 & 0554 & $35^{\circ} 47.37^{\prime}$ & $118^{\circ} 02.21^{\prime}$ & 9.4 & 1.9 & Sierra \\
\hline 17 & Apr. 12, 1984 & 2245 & $35^{\circ} 45.51^{\prime}$ & $117^{\circ} 59.71^{\prime}$ & 7.7 & 1.9 & Sierra \\
\hline \multirow[t]{4}{*}{18} & Aug. 16,1985 & 0753 & $36^{\circ} 11.31^{\prime}$ & $117^{\circ} 53.11^{\prime}$ & 9.6 & 1.8 & Coso \\
\hline & & $0205^{\dagger}$ & & & & 1.9 & \\
\hline & & 0252 & & & & 1.7 & \\
\hline & & 0752 & & & & 1.7 & \\
\hline 19 & Aug. 22,1985 & 0052 & $35^{\circ} 54.18^{\prime}$ & $117^{\circ} 43.56^{\prime}$ & 9.5 & 2.1 & Coso \\
\hline
\end{tabular}

Earthquakes $2,5,6,7,8,11,18$, and 19 were located with Coso stations within $60 \mathrm{~km}$ and the Coso velocity model (Table 2). The Coso stations are CLC, LRM, SRT, TOW, WBM, WCH, WCP, WCS, WCX, WHS, WMF, WNM, WRC, WRV, WSC, WSH, and WVP. Earthquakes 3, 9, 10, 15, 16, and 17 were located with Sierra stations within $60 \mathrm{~km}$ and the Sierra velocity model. The Sierra stations are ISA, WAS, WBM, WBS, WCH, WCO, WHF, WHV, WJP, WKT, WNM, WOF, WOR, WSC, and WWP. Earthquake 4 was located with Sierra stations within $60 \mathrm{~km}$, the Sierra velocity model, and additional stations WCP, WMF, and WRV. Earthquake 12 was located with all stations within $60 \mathrm{~km}$ and the Mojave velocity model.

"This earthquake and earthquake 6 have similar locations and similar seismograms.

${ }^{\dagger}$ This and the two earthquakes below occurred the same day as earthquake 18 and in the same small cluster. They have similar seismograms as well.

$P$ wave first motion focal mechanisms for all of the earthquakes studied indicate that the anomalously low $S V$ wave amplitudes cannot be explained by source radiation effects (Figure 5). Thus, in this study we do not correct the data for source radiation pattern.

\section{EARTHQUAKE LOCATIONS}

Before proceeding with back projection of the data we relocated all of the earthquakes in order to obtain precise hypocentral parameters, especially depth. The large-scale crustal velocity structure in this region is heterogeneous, with the Sierra Nevada, Coso, and Mojave geologic provinces juxtaposed (Figure 2). The available $P$ wave velocity models, however, suggest that the heterogeneity is principally below about $22 \mathrm{~km}$ and above about $3 \mathrm{~km}$ in the crust (Table 2). The individual provinces are heterogeneous at shallow depth, with bedrock in mountains adjacent to unconsolidated sediments in deep basins. In particular, the Indian Wells Valley is filled with about $2-2 \frac{1}{2}$ $\mathrm{km}$ of sediments [Healy and Press, 1964]. One velocity model is not adequate for precisely locating earthquakes that span two of the provinces with stations that span all three provinces. To partially avoid the problem of crustal heterogeneity, we located each event using the velocity model of the province within which the event lies and only stations within or very near the edge of the province and closer than $60 \mathrm{~km}$. The $P$ waves used to locate the earthquakes (except for earthquake 12) thus have ray paths predominantly within a single crustal province. We located each earthquake separately, and since no station corrections have been determined for this seismic array, none were used. Data from stations with large residual travel times (espe- cially TOW and SRT that lie above the low-velocity sediments) were automatically excluded from the earthquake location calculations. Table 1 gives the earthquake locations and details of the stations and velocity model used to locate each earthquake. We feel that the earthquakes have epicentral uncertainties of less than $2 \mathrm{~km}$ and depth uncertainties of about $2-4 \mathrm{~km}$ depending on the distance to the nearest seismometer.

In this study we back projected the attenuation data along ray paths calculated assuming laterally homogeneous velocity models. We feel that these ray paths are sufficiently precise, since the lateral velocity variations in the depth range 3 to 12 $\mathrm{km}$ appear minimal. The stronger lateral velocity variations in the upper few kilometers of the crust will affect the ray paths little, since all of the earthquakes we study have hypocenters deeper than $3 \mathrm{~km}$, and most are deeper than about $6 \mathrm{~km}$.

TABLE 2. Crustal Velocity Models

\begin{tabular}{cccccc}
\hline \multicolumn{2}{c}{ Coso } & \multicolumn{2}{l}{ Sierra } & \multicolumn{2}{l}{ Mojave } \\
\hline $\begin{array}{c}V_{p}, \\
\mathrm{~km} / \mathrm{s}\end{array}$ & $\begin{array}{c}\text { Depth to Top } \\
\text { of Layer, } \mathrm{km}\end{array}$ & $\begin{array}{c}V_{p}, \\
\mathrm{~km} / \mathrm{s}\end{array}$ & $\begin{array}{c}\text { Depth to Top } \\
\text { of Layer, } \mathrm{km}\end{array}$ & $\begin{array}{c}V_{p}, \\
\mathrm{~km} / \mathrm{s}\end{array}$ & $\begin{array}{c}\text { Depth to Top } \\
\text { of Layer, } \mathrm{km}\end{array}$ \\
\hline 3.5 & 0.0 & 5.4 & 0.0 & 5.5 & 0.0 \\
4.8 & 0.2 & 5.8 & 1.0 & 6.2 & 5.5 \\
5.6 & 1.0 & 6.2 & 8.0 & 6.7 & 27.0 \\
6.0 & 3.0 & 6.9 & 22.0 & 7.8 & 31.0 \\
6.3 & 12.5 & 7.9 & 40.0 & & \\
7.8 & 24.5 & & & & \\
\hline
\end{tabular}

Coso - Walter and Weaver [1980]; Sierra - Jones and Dollar [1986]; Mojave - Hadley and Kanamori [1977] 


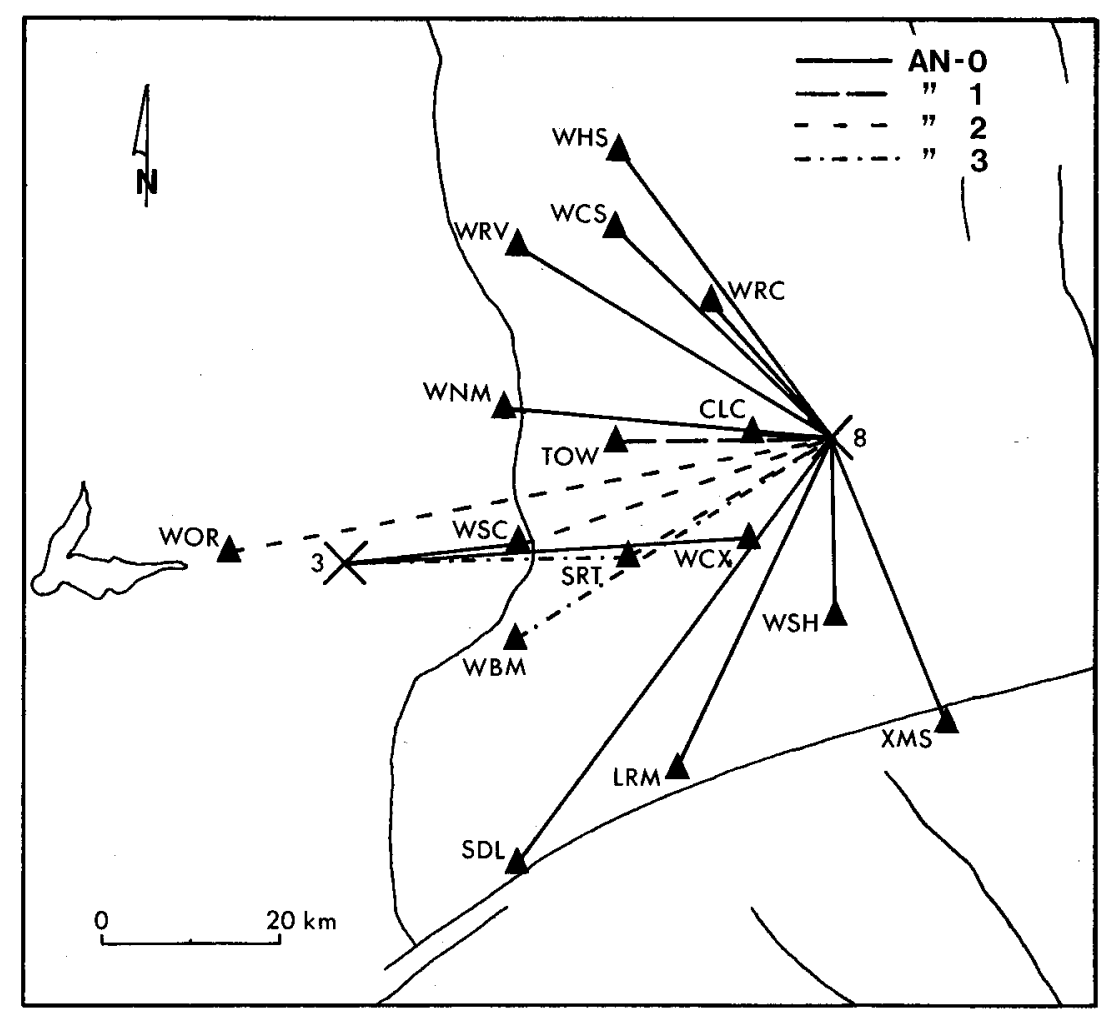

Fig. 3a. Map of ray paths from events 3 and 8 . These events illustrate the localized nature of the $S V$ wave attenuation anomalies. The attenuation numbers $(A N)$ corresponding to the different ray path line types are defined in the upper right comer.

Heterogeneity due to local anomalies may affect the ray paths more significantly, such as lateral refractions around an anomalously slow region which would produce a smaller image of the anomaly.

\section{RESULTS}

The data used in this study are sufficient to resolve the gross $S V$ wave attenuation structure in the shallow crust of the Indian Wells Valley-Coso region. Resolution is best where rays from many different azimuths and takeoff angles intersect, and is poorest where intersections are few. The rays with anomalous (AN 2 or 3) seismograms traverse anomalously attenuating crust somewhere along their travel paths, whereas the rays that give normal ( $A N \quad 0)$ seismograms do not traverse anomalously attenuating crust anywhere along their travel paths.

\section{Visual Madel}

We are attempting to find the attenuation structure that can explain the qualitative data most simply. For simplicity we first assume straight ray paths through a homogeneous crustal velocity structure. If we look first at the surface projections of the most attenuating ray paths, we see that there is a single area through which most of the rays pass (Figure 6). Obviously, an $S V$ wave attenuation anomaly of the size outlined and extending over many kilometers in depth would explain the data most simply [Sanders et al., 1984]. Of course, a more complicated model with many smaller anomalies could also explain the data.

Next we examine the data plotted on vertical cross sections (Figure 7). Each cross section is constructed along an alignment of earthquakes and stations $( \pm$ a few kilometers), so that several ray paths lie entirely within the plane of the section. In addition to providing constraint on the lateral dimensions of the attenuation structure, these cross sections, more importantly, help constrain the depth dimension of the structure. Figure $7 a$ shows the locations of the five cross sections. The Sierra Nevada frontal fault is drawn in each section where appropriate (assuming a $60^{\circ}$ east dip normal to the local fault strike). This projection of the fault may be somewhat idealized in the upper $2-3 \mathrm{~km}$, since gravity data suggest that the shallow fault zone is more likely a series of step faults [Healy and Press, 1964]; however, it is precise enough for our purposes. We plot outof-plane rays where they intersect the plane of a section. $A N 0$ ray paths plot as solid lines (in-plane) or hollow circles (out-ofplane), AN 1 rays as long-dashed lines or half circles, $A N 2$ rays as short-dashed lines or solid circles, and $A N 3$ rays as dash-dot lines or solid circles. The sections have a vertical exaggeration of 4 .

In each cross section, the $A N 0, A N 2$, and $A N 3$ rays that lie in the plane of the cross section together with the out-of-plane $A N 0$ rays that pass through the cross section provide the constraints on the attenuation structure. Somewhere along each $A N$ 2 and $A N 3$ ray a region must exist that anomalously attenuates $S V$ waves. The $A N 0$ data indicate the regions of normally attenuating crust. The out-of-plane $A N 2$ and $A N 3$ data do not help constrain the in-plane attenuation structure; they can be, however, supportive information.

In cross section A-A' (Figure $7 b$ ) AN 0 rays to stations TOW and LRM bound above and below the $A N 3$ ray from earthquake 18 to station SRT and the $A N 2$ and $A N 3$ rays from earthquake 11 to stations TOW and SRT. Combined with the out-of-plane $A N 0$ rays and the $A N 0$ ray from earthquake 11 to station WMF, these data strongly suggest a region of high $S V$ wave attenuation located beneath stations TOW and SRT above $3 \mathrm{~km}$ 


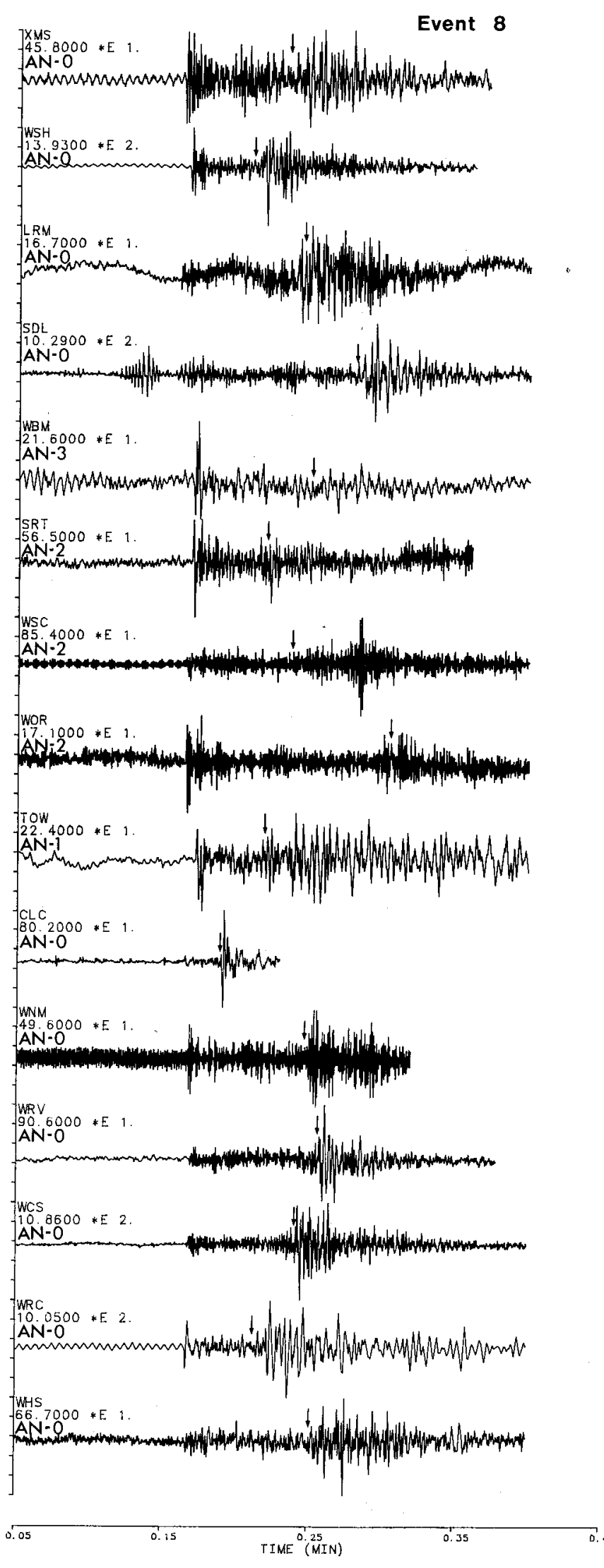

Fig. 3b. Seismograms from event 8 . On each seismogram the expected $S V$ wave arrival is marked by an arrow, and the qualitative attenuation number $(A N)$ is indicated. Note the low $S V$ wave amplitudes at stations WBM, SRT, WSC, and WOR, which are in a particular azimuthal range from the event. depth but not extending to the surface. Additional complexity may be required to explain the $A N 2$ ray from earthquake 11 at station TOW. $A N 0$ rays indicate that the upper $5 \mathrm{~km}$ or so of crust beneath stations WMF and WVP in the Coso Range is not anomalously attenuating. Similarly, in section C-C' (Figure 7d) the data suggest a shallow region of high attenuation coincident with that in section A-A'; however, in addition they suggest a deeper attenuating region beneath stations WSC and SRT at a depth of about 5 to $8 \mathrm{~km}$. The data in section D-D' also suggest the existence and approximate location of the shallow attenuation region. The data in sections B-B' and E-E' provide further evidence for the lateral and depth extent of the shallow attenuating region.

From this analysis we can identify two volumes of high $S V$ wave attenuation beneath western Indian Wells Valley, roughly beneath seismograph stations TOW, SRT, and WSC (Figure 7a). One volume lies in the very shallow crust, above about $3 \mathrm{~km}$ depth (assuming straight rays), and another lies between about 5 and $8 \mathrm{~km}$ depth beneath the westem part of the shallower volume. Both lie near the Sierra Nevada frontal fault zone. In addition, the data suggest no anomalous $S V$ wave attenuation in the upper $5 \mathrm{~km}$ or so beneath the Coso geothermal area. These are the principal results from this simple analysis. The other possible anomalies shown on Figure $7 a$ are not well constrained.

Of course, the straight ray paths we used in this analysis are simplified from the curved paths rays would take through a more realistic layered crust where velocity increases with depth. The rays in a layered crust will travel deeper, in general, and thus, the attenuation structure we imaged is probably somewhat deeper than indicated. In the next section, we present the results of a tomographic back projection inversion of the qualitative amplitude data using both homogeneous and layered velocity models for ray tracing.

\section{Tomographic Inversion}

We inverted the qualitative $S V$ wave amplitude data for the relative $S V$ wave attenuation structure in the Coso-Indian Wells Valley region using a tomographic back projection technique. This inversion provides an objective determination of the relative three-dimensional attenuation structure. The absolute value of attenuation is not obtained. The version of the tomographic scheme used here is the one used by Walck and Clayton [1987] for inversion of $P$ wave residuals. Here the method is applied to attenuation data instead of travel time data. A similar application was made previously to attenuation data for the Imperial Valley, California [Ho-Liu et al., 1986].

In the tomographic inversion for velocity structure the crust under study is divided into blocks within which a constant slowness is assumed. Then the problem is formulated as

$$
t_{i}=\sum_{j} l_{i j} s_{j}
$$

where $t_{i}$ is the travel time of the $i$ th ray, $l_{i j}$ is the path length of the $i$ th ray in the $j$ th block, and $s_{j}$ is the slowness of the $j$ th block. A straightforward modification of (1) for attenuation data is

$$
\ln \left(a_{i}\right)=\sum_{j} m_{i j} k_{j}
$$

where $a_{i}$ is the amplitude of the $i$ th ray, $k_{j}$ is the attenuation constant of the $j$ th block, and $m_{i j}=\pi f l_{i j} s_{j}, f$ being the frequency of the seismic waves. Since (1) and (2) are identical in 


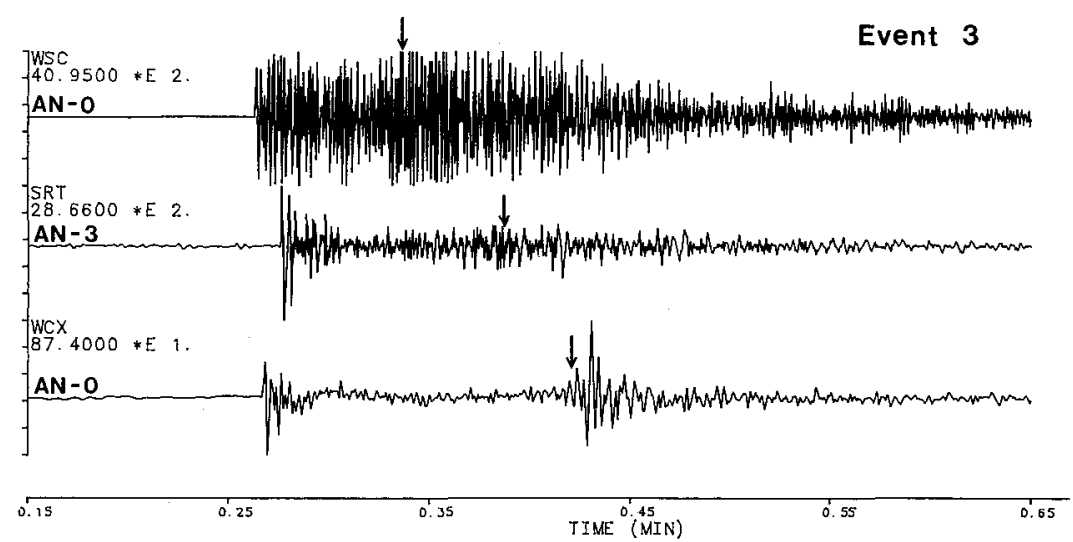

Fig. 3c. Seismograms from event 3. Note the low SV wave amplitude at station SRT compared to stations WSC and WCX. These stations lie on nearly the same azimuth from the event but at different takeoff angles: WSC, $113^{\circ}$; SRT, 101 ; WCX, $96^{\circ}$.
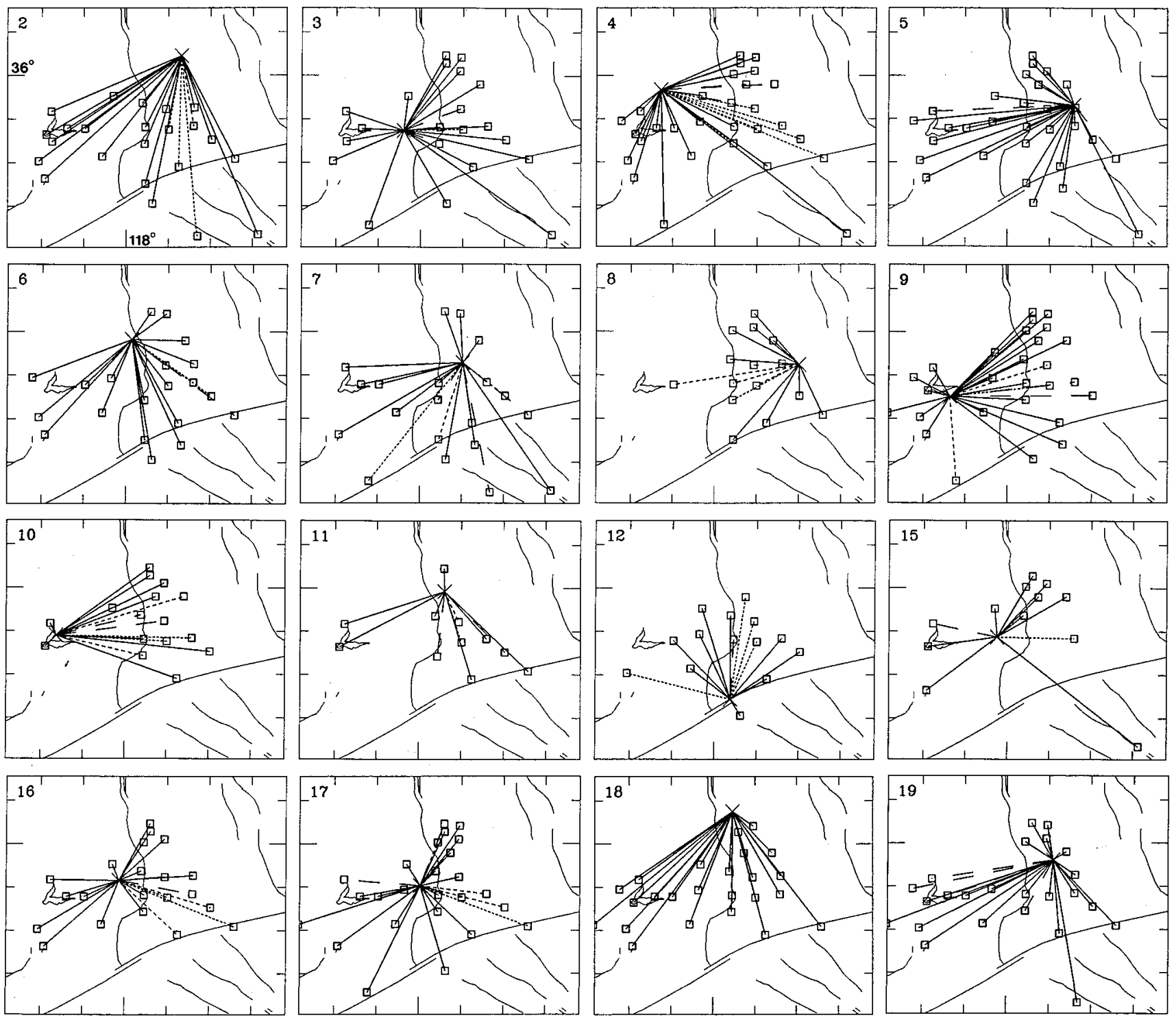

Fig. 4. Maps showing the surface projection of the source-station paths used in this study. Each frame contains the data from one earthquake. The earthquake number corresponding to Table 1 is shown in the upper left corner of each frame. Each earthquake epicenter is marked with a cross and the seismic stations with squares. The different line types represent the $A N$ number of the corresponding seismograms: $A N$ 0, solid line; $A N$ 1, long dashes; $A N 2$, medium dashes; $A N$ 3, short dashes. See Figure 2 for geographic information. 
TABLE 3. Ray Attenuation Numbers and $A_{s} / A_{p}$ Ratios

\begin{tabular}{|c|c|c|c|c|c|c|c|c|c|c|c|c|c|c|c|c|}
\hline \multirow[b]{2}{*}{ Station } & \multicolumn{16}{|c|}{ Event } \\
\hline & 2 & 3 & 4 & 5 & 6 & 7 & 8 & 9 & 10 & 11 & 12 & 15 & 16 & 17 & 18 & 19 \\
\hline BLK & $0-1.26$ & $0-2.22$ & & $0-5.14$ & & $0-16.50$ & & & & & & $0-6.14$ & & & & \\
\hline CLC & $0-0.63$ & & & $0-1.73$ & $0-1.47$ & & $0-4.0$ & & & & & & $0-1.21$ & & $0-6.00$ & $0-1.95$ \\
\hline DTP & $0-1.67$ & $0-2.16$ & & $0-1.97$ & $0-3.44$ & $0-1.88$ & & & & & $0-2.18$ & & & $0-1.18$ & & \\
\hline ISA & $0-3.26$ & & $0-13.33$ & & & & & $0-1.71$ & $0-4.52$ & $0-1.45$ & & $0-1.22$ & & & $0-1.88$ & $0-0.95$ \\
\hline JFS & & & & $0-1.76$ & $0-2.63$ & $0-6.60$ & & $0-1.27$ & & & & & & & & \\
\hline LRM & $3-0.34$ & $0-1.20$ & $0-0.93$ & $0-0.66$ & $0-1.40$ & $0-2.45$ & $0-3.52$ & $0-1.33$ & $0-3.52$ & $0-0.98$ & $0-1.15$ & & $2-0.46$ & $0-1.71$ & $0-1.45$ & $0-1.72$ \\
\hline SBK & $3-0.23$ & & & & & $1-0.57$ & & & & & & & & & & $0-0.89$ \\
\hline $\begin{array}{l}\text { SDL } \\
\text { SNC }\end{array}$ & $0-1.33$ & & $0-1.07$ & $0-1.14$ & $0-3.23$ & $\begin{array}{l}2-0.36 \\
3-0.32\end{array}$ & $0-2.0$ & $2-0.62$ & & & & & & $0-0.83$ & & \\
\hline SRT & $3-0.47$ & $3-0.33$ & $3-0.30$ & $0-1.88$ & $0-0.95$ & & $2-0.61$ & $3-0.44$ & $3-0.29$ & $3-0.45$ & $3-0.33$ & & $3-0.43$ & $1-0.87$ & $3-0.37$ & $0-0.94$ \\
\hline TOW & $2-0.68$ & $1-0.75$ & $3-0.34$ & $0-1.48$ & $0-0.82$ & & $1-0.93$ & $2-0.36$ & $1-0.84$ & $2-0.39$ & $3-0.17$ & & $0-1.22$ & $0-1.12$ & $0-1.62$ & \\
\hline WAS & & & $0-1.20$ & $0-1.37$ & $0-2.13$ & & & $0-1.22$ & & & & & & & $0-2.65$ & $1-0.67$ \\
\hline WBM & $0-1.30$ & $1-0.60$ & $3-0.40$ & $0-1.15$ & $0-1.00$ & $1-0.52$ & $3-0.19$ & $0-1.10$ & $2-0.47$ & $1-0.72$ & & & $0-1.53$ & $0-4.13$ & $1-0.54$ & $1-1.02$ \\
\hline WBS & $0-6.40$ & & $0-1.74$ & $0-6.39$ & $0-1.72$ & $0-0.82$ & & $0-1.96$ & & & $0-2.08$ & & $0-0.72$ & $0-1.47$ & $0-0.95$ & $0-5.42$ \\
\hline WCH & $0-2.05$ & $0-1.02$ & $0-0.80$ & $0-2.43$ & & & & $0-6.50$ & $0-2.50$ & & $0-1.38$ & $0-3.33$ & $0-1.06$ & $0-2.55$ & $0-1.27$ & $0-0.96$ \\
\hline WCO & $0-2.09$ & $0-0.93$ & $0-1.23$ & $0-1.63$ & & & & & & & & & & & & \\
\hline WCP & & $0-3.12$ & $0-1.0$ & $0-1.17$ & & & & $0-1.14$ & $0-1.12$ & & & $0-1.86$ & $0-1.0$ & $0-1.0$ & $0-1.0$ & \\
\hline WCS & & $0-3.51$ & $0-0.70$ & $0-4.40$ & & & $0-4.12$ & $0-2.53$ & $0-0.80$ & & & $0-5.86$ & $0-1.05$ & $0-1.19$ & & $0-1.13$ \\
\hline WCX & $2-0.47$ & $0-1.34$ & $3-0.33$ & $0-1.85$ & $3-0.24$ & $0-1.18$ & & $1-0.82$ & $3-0.36$ & $0-1.69$ & $0-4.71$ & $3-0.38$ & $1-0.64$ & $2-0.44$ & $0-2.73$ & $0-1.22$ \\
\hline WHF & $0-1.42$ & $0-0.97$ & $0-1.38$ & $0-0.88$ & & $0-1.14$ & & & & & & & $0-1.97$ & $0-1.0$ & $0-1.08$ & $1-0.67$ \\
\hline WHS & & $0-6.25$ & $0-0.84$ & & $0-1.34$ & $0-1.15$ & $0-3.79$ & $0-3.47$ & & & & & & $0-0.98$ & $0-1.45$ & $0-1.19$ \\
\hline WHV & $0-3.89$ & $0-2.50$ & $0-6.50$ & $0-4.38$ & $0-3.84$ & & & $0-2.03$ & & & $3-0.26$ & & $0-3.43$ & & $0-1.59$ & $0-1.38$ \\
\hline WJP & $0-2.77$ & & $0-1.96$ & $0-2.00$ & 0.4 .69 & $0-1.17$ & & $0-1.07$ & & & & $0-3.00$ & $0-0.97$ & $0-1.29$ & $0-1.25$ & $0-6.00$ \\
\hline WKT & $0-2.54$ & $0-1.61$ & $0-1.80$ & $1-0.55$ & & $0-5.45$ & & & $0-1.10$ & $0-1.10$ & & $1-0.63$ & $0-1.17$ & $1-0.72$ & $0-4.25$ & $1-0.68$ \\
\hline WMF & & $0-6.25$ & $0-0.68$ & $0-4.11$ & $0-1.24$ & $0-1.09$ & & $0-1.98$ & $0-1.00$ & $0-1.29$ & & & 0.0 .97 & $1-0.63$ & & $0-1.89$ \\
\hline WNM & $0-1.94$ & & $1-0.54$ & $1-0.65$ & & & $0-1.44$ & $0-1.70$ & $1-0.54$ & $0-1.80$ & $0-0.89$ & $0-1.97$ & $0-1.57$ & $0-1.88$ & $0-3.78$ & \\
\hline WOF & & & & & & & & $0-0.98$ & & & & & & $0-2.49$ & $0-3.04$ & $0-2.25$ \\
\hline WOR & $0-3.27$ & & $0-0.87$ & $0-1.69$ & $0-1.39$ & $0-1.16$ & $2-0.59$ & & & & $0-2.36$ & & $0-1.34$ & $0-1.0$ & $0-0.85$ & $0-1.96$ \\
\hline WRC & & $0-1.71$ & $1-0.48$ & $1-0.64$ & $0-1.08$ & $0-1.28$ & $0-1.67$ & $0-1.96$ & $2-0.39$ & & & $0-1.69$ & & & $0-4.50$ & $0-1.16$ \\
\hline WRV & & & $1-0.73$ & $0-1.30$ & & & $0-4.82$ & $0-3.89$ & & & & $0-1.26$ & $0-0.96$ & $2-0.71$ & & $0-1.00$ \\
\hline WSC & $0-2.92$ & $0-1.22$ & $0-0.87$ & $0-2.19$ & & $0-0.97$ & $2-0.69$ & $0-1.00$ & 0.0 .99 & & $1-0.67$ & & $0-1.0$ & $0-1.0$ & $0-2.32$ & $0-2.66$ \\
\hline WSH & $0-0.83$ & $0-1.02$ & $3-0.37$ & $0-1.28$ & $3-0.50$ & $2-0.62$ & $0-1.16$ & $1-1.23$ & $0-2.63$ & $1-0.68$ & $0-2.07$ & & $2-0.58$ & $2-0.39$ & & $0-1.38$ \\
\hline WVP & & & $1-1.0$ & $0-1.0$ & & & & $0-1.56$ & $0-1.09$ & & $3-0.25$ & $0-1.52$ & & $0-1.0$ & $0-1.18$ & \\
\hline WWP & & & $0-0.87$ & $0-0.84$ & $0-1.79$ & & & $0-1.10$ & & & $0-4.03$ & & & $0-1.0$ & $0-2.74$ & $0-3.54$ \\
\hline XMS & $0-1.31$ & $0-1.09$ & $3-0.26$ & $1-0.92$ & $1-0.76$ & $1-0.78$ & $0-0.99$ & & & $0-2.08$ & & & $3-0.32$ & $3-0.25$ & $0-1.95$ & $0-2.08$ \\
\hline
\end{tabular}

$A_{s} / A_{p}=$ ratio peak-to-peak $S$ wave amplitude to $P$ wave amplitude measured within $1 / 2$ second of the expected arrival time.

form, the standard tomographic method can be applied to attenuation data.

One difficulty is that the absolute amplitude data, $a_{i}$, are seldom available. In our case, the qualitative measures of attenuation are used, and therefore we use (2) to determine only the location and shape of the anomalous bodies. By assigning values that are proportional to the degree of attenuation on the left-hand side of (2) we can formally solve (2) for $k_{j}$. The absolute value of $k_{j}$ depends on the values assigned, and thus has no physical significance in this study. Inasmuch as the shape of the attenuating body mainly determines the spatial distribution of the attenuated paths, we feel that the geometry of the anomalous body can be approximately determined by this inversion.

In this inversion the crust is parameterized into blocks $2 \times 2 \times 1 \mathrm{~km}$ (north-south, east-west, vertical). The values of $a_{i}$ used are $0.1,0.4$, or 1.0 , depending on the qualitative attenuation number given the particular datum $(A N 3, A N 2$, or $A N 0$, respectively). These numbers correspond to the approximate characteristic $S V$ to $P$ wave amplitude ratio in each group. Since we are inverting for the relative attenuation structure the absolute values of these numbers are not important, and inversions with different sets of values of $a_{i}$ give essentially the same structure.

We can evaluate the resolution of the tomographic inversion of the data by analyzing the number and azimuths of rays passing through each block. When comparing the relative resolution of the anomalies in two blocks, the block that has been traversed by a larger number of rays from a wider range of azimuths and takeoff angles is the better resolved of the two blocks. Figure 8 shows graphically the number of rays that traversed each block in the model (the hit count). These hit counts are from the inversion using the layered Coso velocity structure. The dot size increases with the number of rays that traversed a block. For each depth slice, we can see where data density is high and, thus, where the resolution of the inversion should be improved. The resolution, however, also depends strongly on the azimuthal coverage, which can be evaluated

TABLE 4. $A_{s} / A_{p}$ Statistics by Attenuation Number

\begin{tabular}{lcccc}
\hline & \multicolumn{5}{c}{ Attenuation number } \\
\cline { 2 - 5 } & \multicolumn{1}{c}{0} & 1 & 2 & 3 \\
\hline Number of & \multicolumn{1}{c}{253} & 32 & 17 & 27 \\
Seismograms & 2.11 & 0.72 & 0.52 & 0.33 \\
Average $A_{s} / A_{p}$ & 1.78 & 0.16 & 0.12 & 0.08 \\
$\sigma$ & 16.50 & 1.23 & 0.71 & 0.50 \\
Maximum $A_{s} / A_{p}$ & 0.63 & 0.48 & 0.36 & 0.17 \\
Minimum $A_{s} / A_{p}$ & & &
\end{tabular}


өq2 30 Dot 831352

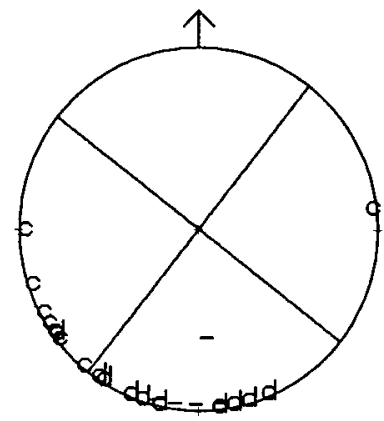

eq6 $27 \operatorname{Jan} 840119$

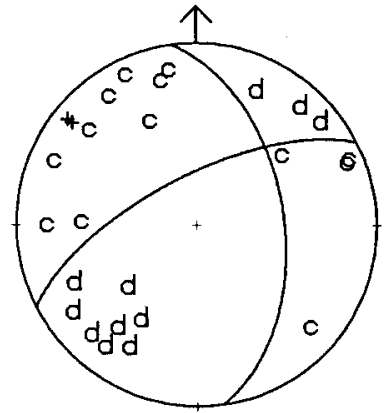

eq10 24 Jul 832046

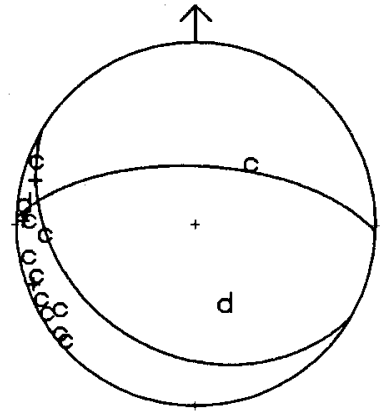

๑q16 11 Apr 840554

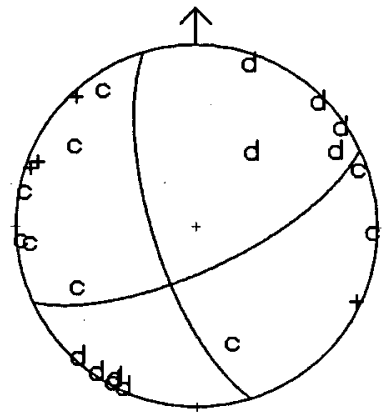

eq3 24 Feb $84 \quad 1343$

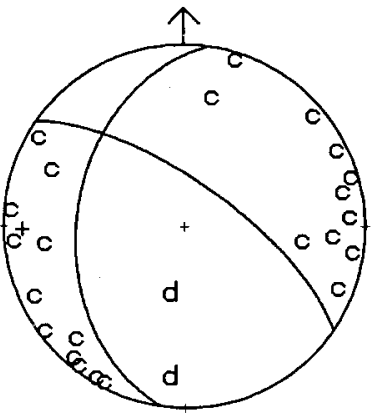

eq7 20 Jan 840118

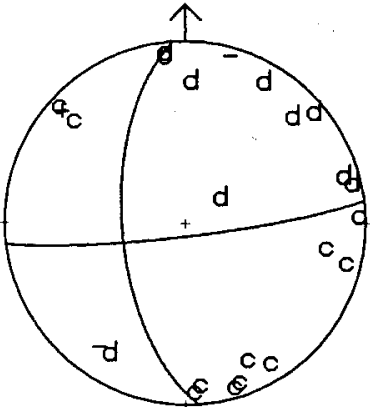

eq11 31 Jul 831608

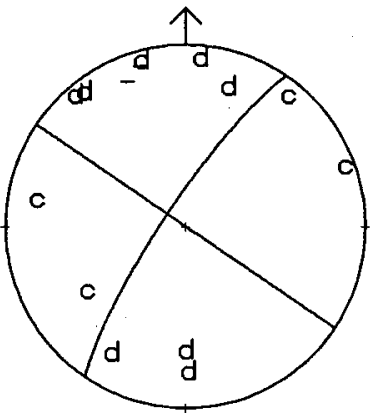

eq17 12 Apr 842245

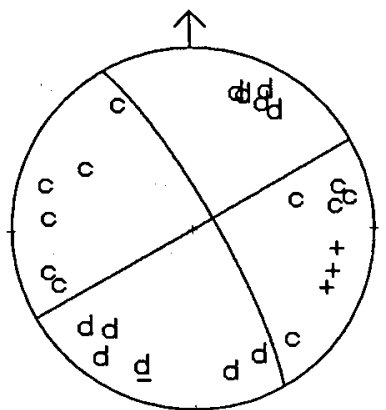

eq4 08 Feb 841156

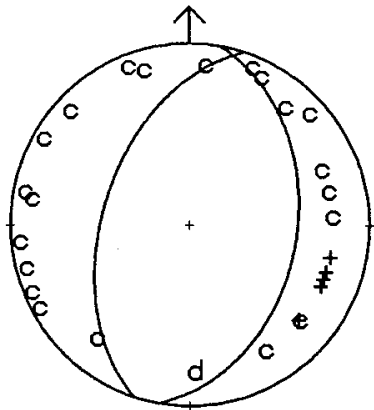

eq8 06 Oct 830720
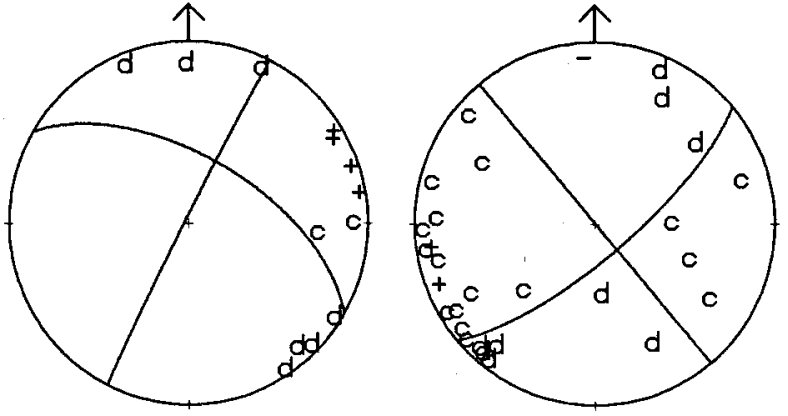

eq12 06 Apr 840906
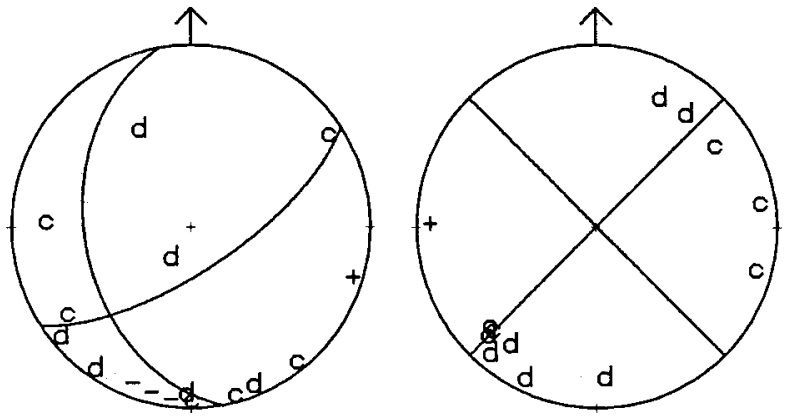

eq18 16 Aug 850205

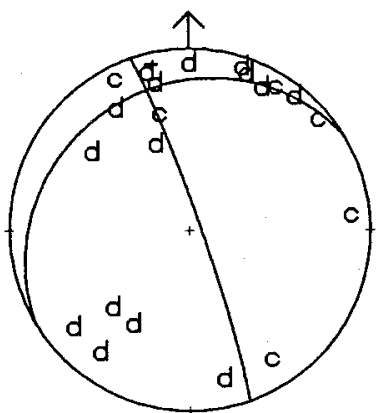

eq5 og Jan $84 \quad 1518$

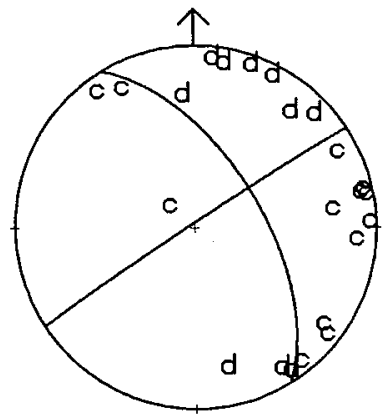

eq9 02 Feb 840824

Fig. 5. Focal mechanisms of the 16 earthquakes studied. The $P$ wave first motion symbols are defined as follows: normal $S V$ waves: c, compression; d, dilatation; attenuated $S V$ waves: plus, compression; minus, dilatation. Lower hemisphere, equal area projection. These plots indicate that the anomalous $S V$ wave amplitudes are not a source effect.

from Figures 4 and 6. From these figures we feel that the inversion resolution should be best near the central and northern parts of the model (between depths of 1 and $9 \mathrm{~km}$ ) and decrease elsewhere. There may be a tendency for anomalies to smear along predominant ray azimuths in the peripheral regions where azimuthal coverage is limited [Humphreys, 1985].

We inverted the data first using ray paths traced through a homogeneous velocity model so that we could compare the 


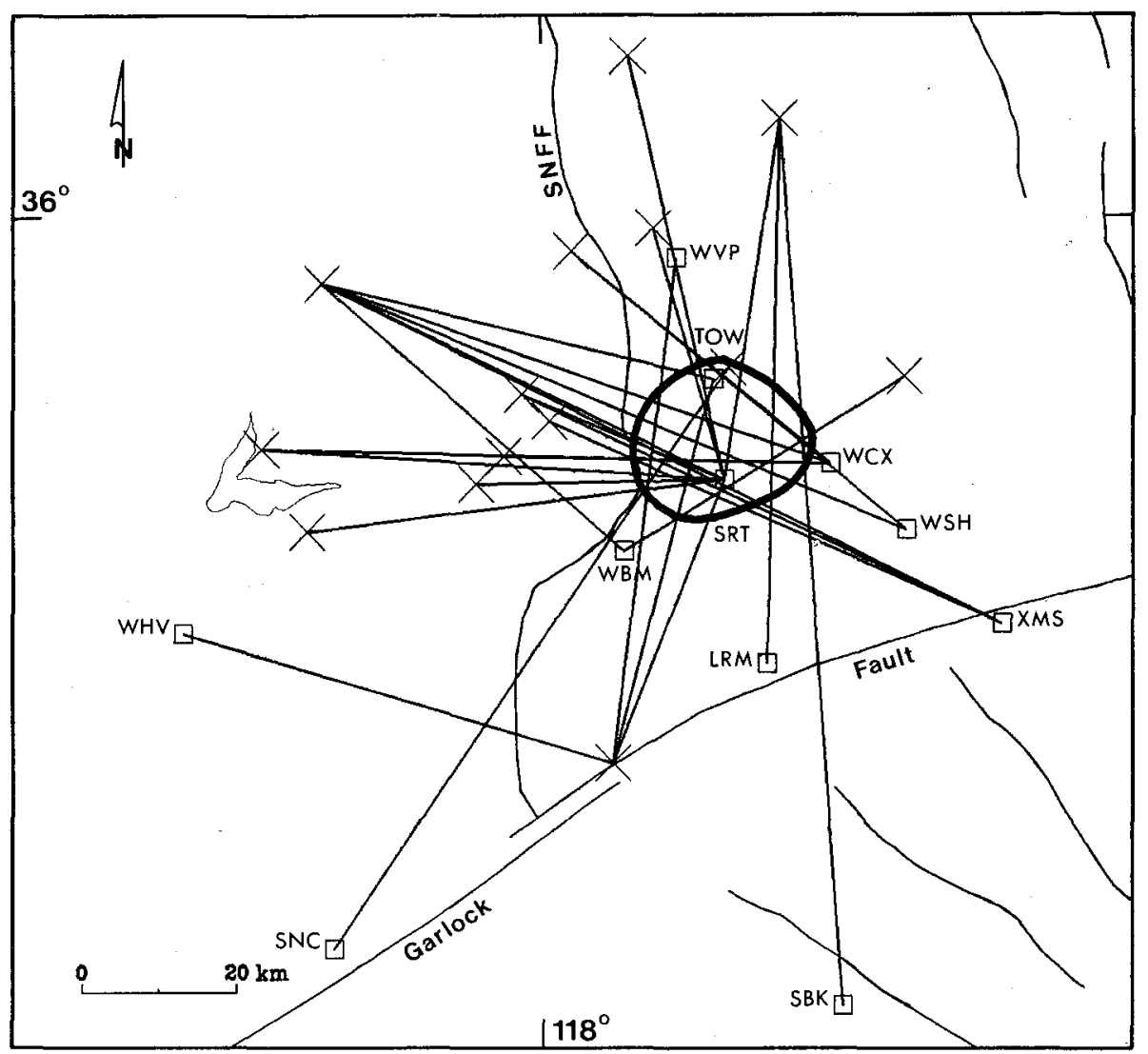

Fig. 6. Map of very attenuating ray paths $(A N 3)$. The oulline of the single, simple anomaly which can explain most of the observations is shown. A. cross denotes earthquake epicenter, square, station location.

results with the forward model described earlier. Figure 9 shows the inversion results. Each frame in Figure 9 shows a separate depth slice of the crust. The dots indicate the $k$ (attenuation) value of each block; only values from blocks with at least two rays traversing them are plotted. The size of a dot indicates the magnitude of the attenuation anomaly in the corresponding block (the absolute magnitude is not significant); the smallest dots indicate no attenuation anomaly, and the larger dots indicate stronger anomalies (highly attenuating). The block results were smoothed laterally with a nine-point filter before plotting. In the $0-1 \mathrm{~km}$ depth range many small anomalous areas are indicated, each one corresponding to the crust just below a seismic station (compare with Figure 2). Each of these seismic stations recorded normal $S V$ waves from many earthquakes (in addition to some anomalous $S V$ waves), suggesting that the crust immediately below each station is not abnormally attenuating. Thus, these anomalies are probably spurious and indicate lack of resolution near the surface with this data set. In the $1-3,3-5$, and $5-7 \mathrm{~km}$ depth ranges the principal attenuation structure mapped from visual inspection (Figure 7) is also imaged by the inversion. This gives us confidence that the inversion correctly resolves structure in the areas where ray coverage is good. The structures near the edges of the ray coverage (where hit count is low and azimuthal coverage limited) are poorly resolved and considered spurious.

We next inverted the data using ray paths traced through the layered crustal velocity model determined for the Coso area (Table 2). The results of this inversion should provide a better estimate of the depth of the attenuation structure. Figure 10 (same format as Figure 9) shows the results for five depth ranges. The principal high-attenuation anomaly now lies in the 3-5 $\mathrm{km}$ depth range beneath the Indian Wells Valley (compared to $1-3 \mathrm{~km}$ assuming straight ray paths). This anomaly extends into the $5-7 \mathrm{~km}$ depth range where it lies further west. The streaking of these anomalies in an east-west direction may be due to a predominant ray azimuth in that direction. Anomalies at the edges of the model are poorly constrained.

We can compare the $S V$ wave attenuation inversion results with those from the inversion of $P$ wave travel time delays in the same area by Walck and Clayton [1987] (they also used the Coso velocity model to calculate ray paths). We compare the results in three depth ranges, 3-5, 5-7, and 7-9 km (Figure 11), and focus on the best-resolved $S V$ wave attenuation anomalies and $P$ wave travel time anomalies in the lower center of each frame. In the $3-5 \mathrm{~km}$ depth range a large anomaly is imaged just east of the Sierra Nevada frontal fault from both the $P$ and $S V$ wave data. The details of the geometry of the $P$ and $S V$ wave anomalies are somewhat different (the $S V$ wave anomaly may be streaked east-west due to azimuthal bias); however, the principal location relative to the fault is the same. In the 5-7 $\mathrm{km}$ depth range an anomaly beneath the southwestern end of the shallower anomaly is also imaged by both the $P$ and $S V$ wave data, though the details vary. Another coincidence is seen in the 7-9 $\mathrm{km}$ depth range north of the shallower anomalies. Both data sets indicate no anomaly beneath Coso (east of $118^{\circ}$ and north of $36^{\circ}$ ) in the relatively well sampled section of the crust above about $5 \mathrm{~km}$. Though the match is not exact (which may be expected since the ray data are not the same), the general correlation between the principal $S V$ wave attenuation and $P$ wave travel time anomalies is good. This suggests that the two 

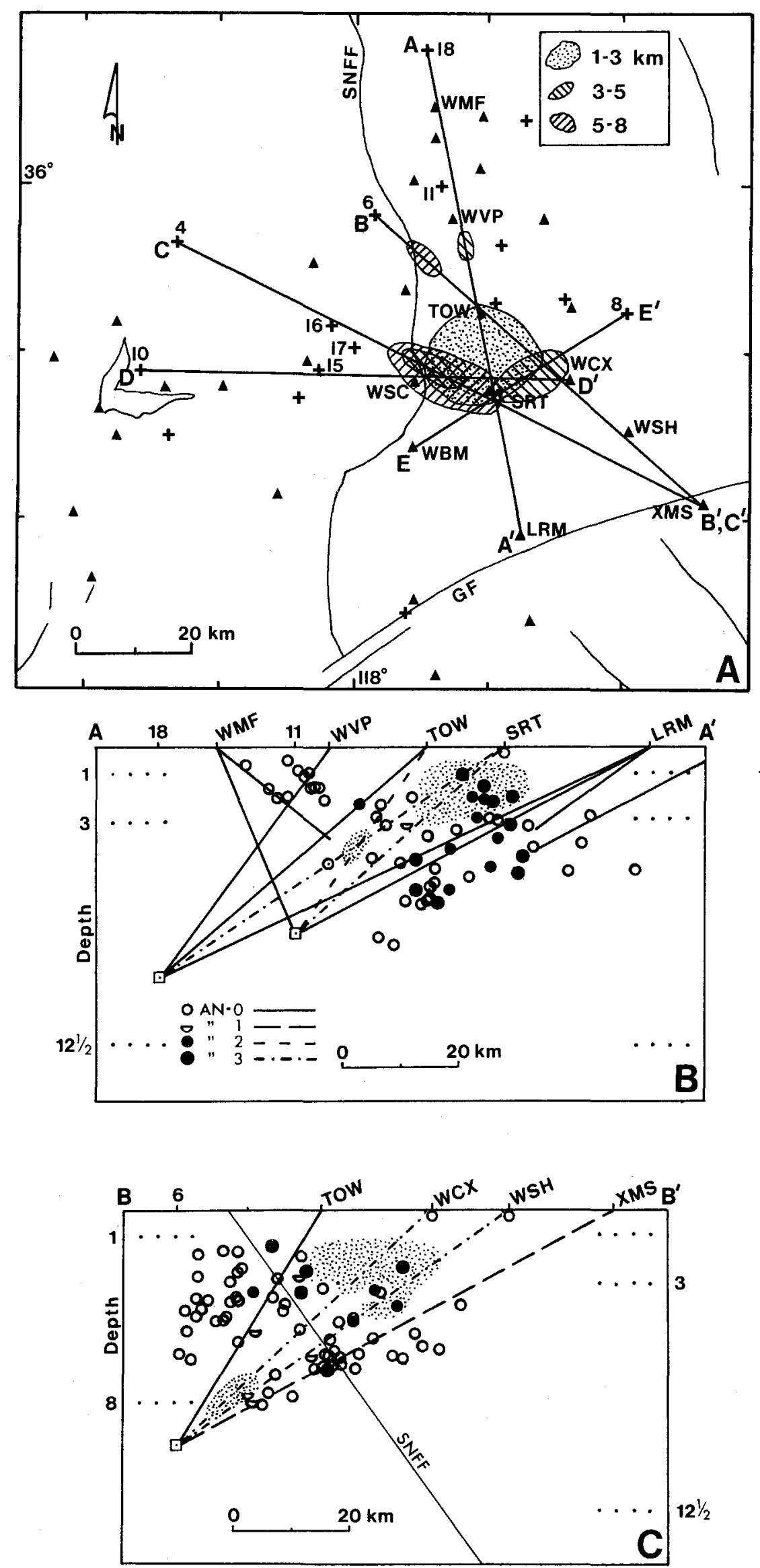

Fig. 7. Figure $7 a$ is a map showing locations of cross sections and regions of anomalously high $S V$ wave attenuation. The depths of the anomalies are indicated by stippling and hatching. Figures $7 b-7 f$ show cross sections A-A', B-B', C-C', D-D', and E-E', respectively. The circular symbols show where out-of-plane rays intersect the cross section; these are defined in the lower left comer of Figure $7 b$. We have assumed straight ray paths. Possible regions of high attenuation are indicated by stippling. The positions of velocity boundaries for the appropriate crustal models (Table 2) are marked at the edges of each section. SNFF, Sierra Nevada frontal fault; GF, Garlock fault. Depths are in kilometers. Vertical exaggeration of 4. 

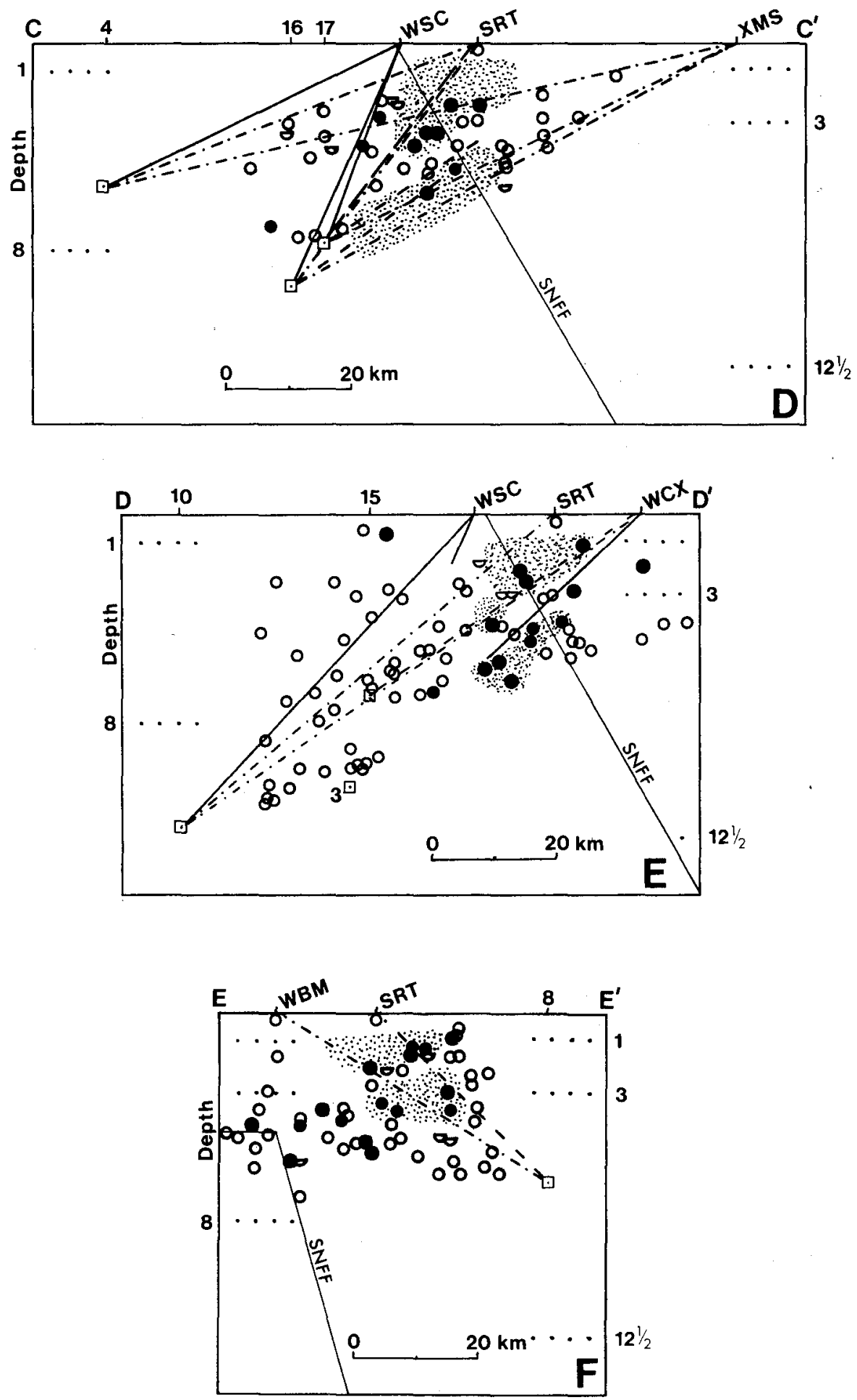

Fig. 7. (continued)

different wave transmission phenomena are sensitive to the same conditions in this anomalous crustal area. In the next sections, we discuss other observations in relation to these anomalies.

\section{EARTHQUAKE SWARMS}

The area of the observed $S V$ wave attenuation and $P$ wave velocity anomalies was also the site of swarms of small earth- quakes from February 1982 to March 1983. This seems to have been the most intensive swarm activity in Indian Wells Valley in the past 50 years [Given et al., 1983]. Figure 12 shows the epicentral locations of these earthquakes during four principal periods of swarm activity. These plots illustrate the spatial and temporal relations between clusters of earthquakes in the four time periods. All of the earthquakes occurred within a region bounded by stations TOW and SRT (similar to the diameter of 
$0-1 \mathrm{Km}$

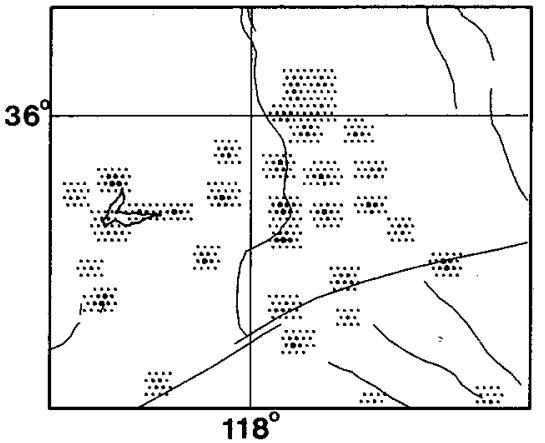

$5-7 \mathrm{Km}$

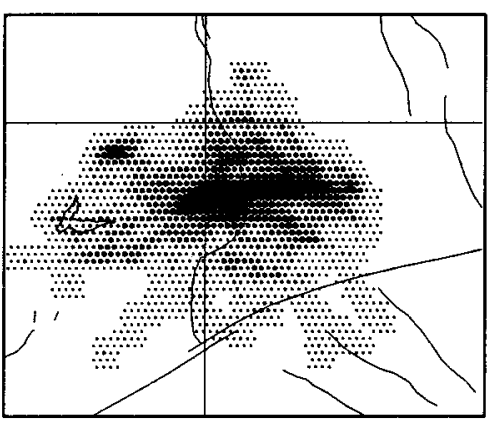

$1-3 \mathrm{Km}$

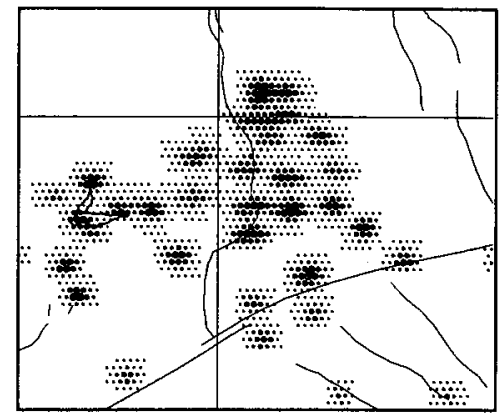

$7-9 \mathrm{Km}$

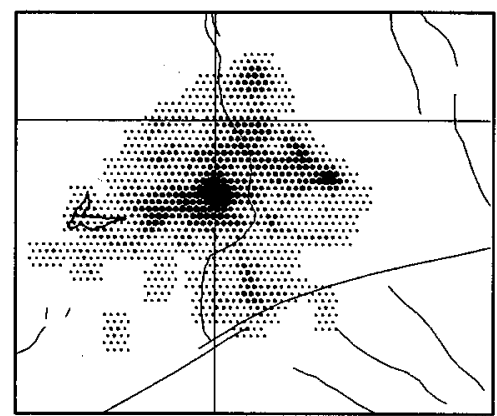

3-5 Km

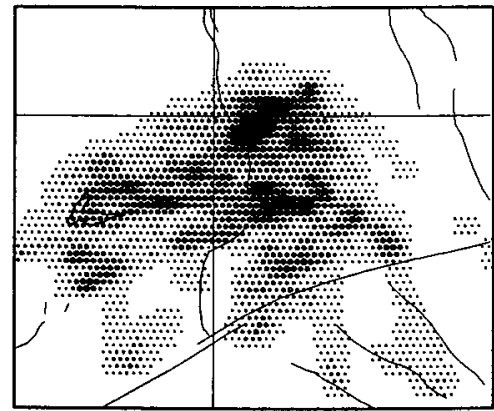

Coso region: Inversion Hitcount

Fig. 8. Maps showing the hit count for various depth slices of the tomographic model. The data are smoothed with a nine-point filter. The size of each dot indicates the number of rays which traversed that block in the model (legend is in the lower right corner). Where data density is greatest, the inversion resolution is better. Resolution is also strongly dependent on azimuthal coverage, which is indicated in Figures 4 and 6 . The rays were traced through the Coso velocity model (Table 2).

$0-1 \mathrm{Km}$

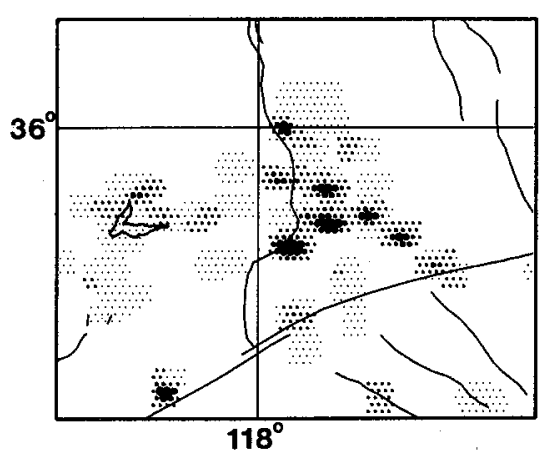

5-7 Km

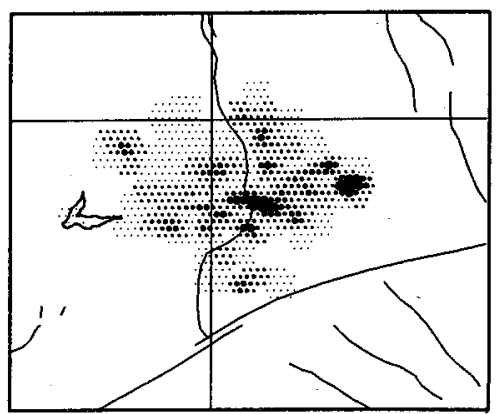

$1-3 \mathrm{Km}$

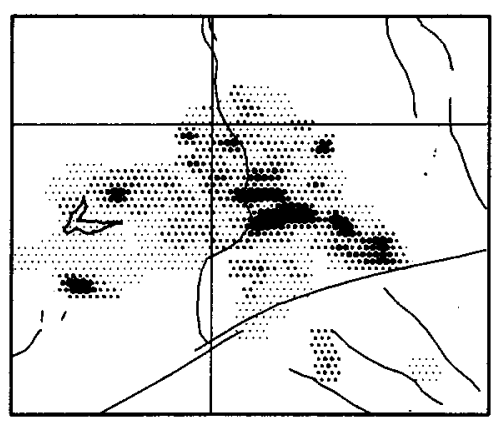

7-9 Km

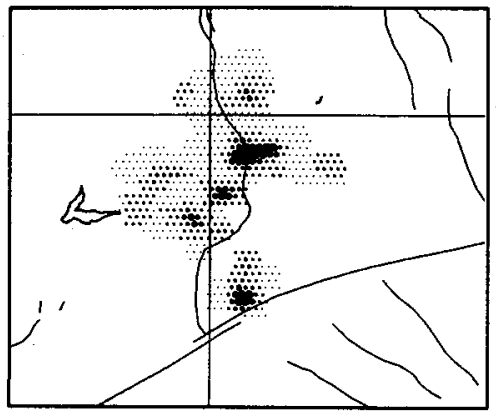

3-5 Km

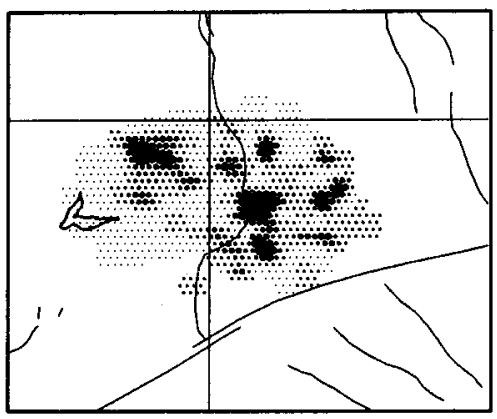

Coso region: Halfspace Inversion

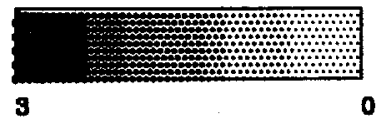

Fig. 9. Maps showing the results of a back projection inversion of the attenuation data for various depth ranges. The data are smoothed with a nine-point filter. The velocity model used for ray tracing is a homogeneous half-space. Shading scale: the degree of attenuation ranges from 3 (very attenuating) to 0 (normal). For geographic reference see Figures 2 and $7 a$. 
$0-1 \mathrm{Km}$

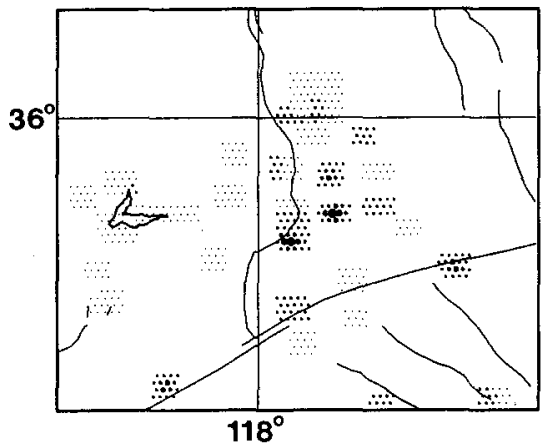

5-7. $\mathrm{Km}$

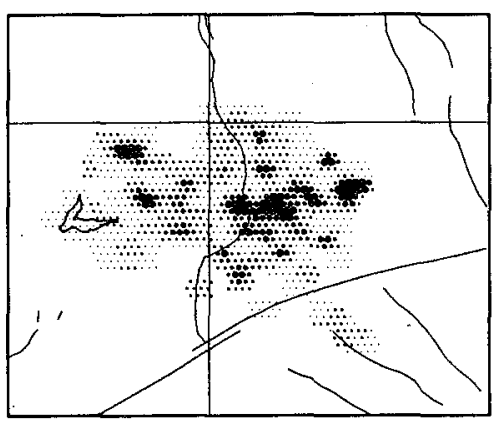

$1-3 \mathrm{Km}$

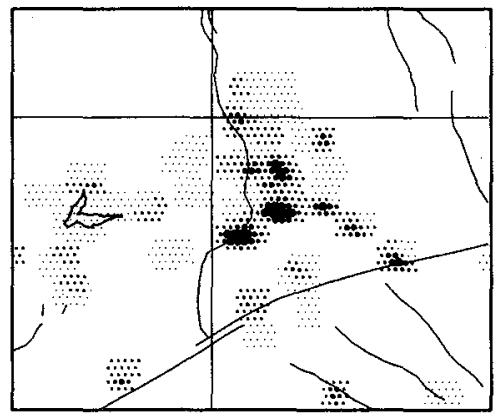

$7-9 \mathrm{Km}$

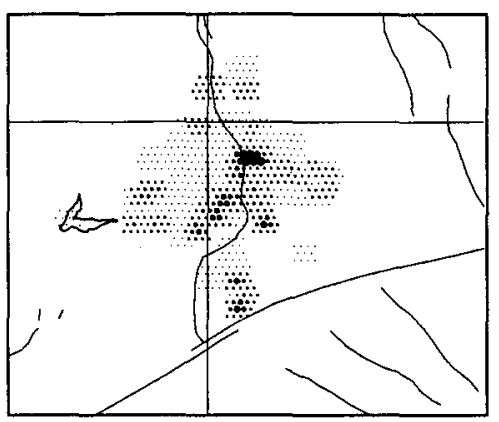

3-5 Km

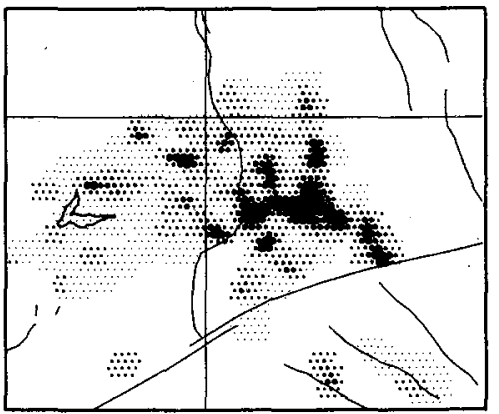

Coso region: WW model Inversion

Fig. 10. Maps similar to Figure 9 except that the Walter and Weaver [1980] (WW) Coso velocity model is used for ray tracing (Table 2). The principal attenuation anomalies lie in the $3-5$ and $5.7 \mathrm{~km}$ depth ranges.

the shallow attenuation anomaly); however the locus of activity was not constant during the different periods, and earthquake activity moved first northward and then southward from an initial central cluster. Bent et al. [1986], who relocated the swarm earthquakes, found that most hypocenters were at $5-10 \mathrm{~km}$ depth. They also noted the general southward migration of epicenters with time.

Small earthquake swarms are apparently common in the Coso volcanic-geothermal field [Walter and Weaver, 1980]. The cause of this type of earthquake occurrence, though, is not certain, as earthquake swarms, in general, are not unique to any one geologic environment and cannot be related to a single geologic process. The swarms at Coso, individual events of which have strike-slip or normal focal mechanisms, have been interpreted as occurring in an area of local crustal spreading between strike-slip fault segments [Weaver and Hill, 1979]. This interpretation follows from a model suggested by Hill [1977] to explain data from three other volcanic-geothermal areas. In his model earthquake swarms occur on strike-slip fault segments which connect magma-filled dikes, and the earthquake occurrence is controlled by a balance between fluid pressures and tectonic stresses. Bent et al. [1986] have suggested, based on focal mechanisms (strike-slip and normal) and relocated epicenters, that the earthquake swarms in Indian Wells Valley occurred on two en-echelon strike-slip faults offset by a zone of extension. Thus, the Indian Wells Valley swarms may be related to an interaction of faults and volcanic fluids similar in manner to that suggested by Hill [1977], though other explanations are possible.

\section{DISCUSSION}

The analysis presented above indicates the existence of regions that severely attenuate $S V$ waves in the shallow crust beneath the Coso-Indian Wells Valley-southern Sierra Nevada area. These anomalous volumes do not lie beneath the young Coso volcanic centers, but rather about $20-30 \mathrm{~km}$ south beneath Indian Wells Valley. No anomalous $S V$ wave attenuation is evident beneath the volcanic centers, at least above a depth of about $5 \mathrm{~km}$. In Indian Wells Valley $P$ waves do not seem to be abnormally attenuated, though anomalously slow $P$ wave velocities are reported for the crust there [Walck and Clayton, 1987].

These observations raise two obvious questions: (1) what conditions in the anomalous region of the crust beneath Indian Wells Valley are causing the observed anomalies? and (2) why are similar shallow anomalies not seen beneath the young Coso volcanic area? In order to explore these questions we require a knowledge of the geological and geophysical character of the Coso area and other areas of the eastem Sierra Nevada front.

As described in the introductory section, the Coso volcanic field is a Quaternary silicic volcanic center located along the eastern Sierra front. Other Quaternary volcanic centers exist along the eastern Sierra front at Long Valley and Big Pine (Figure 1). Studies by Bailey et al. [1976], Duffield et al. [1980], Bacon et al. [1980], and Huber [1981] indicate that the volcanism at Long Valley and Coso is spatially and temporally related to the local extensional faulting. Studies of heat flow and geologic relations at other silicic volcanic centers in the western United States also support a relation between the volcanism and extensional tectonics [Eichelberger and Gooley, 1977; Lachenbruch and Sass, 1978; Shaw, 1980]. These precedents suggest that we could reasonably expect to find volcanism at other locations along the eastern Sierra Nevada fault zone. The zone of Quaternary volcanism along the Sierran front near Long Valley extends for $40 \mathrm{~km}$ indicating that volcanism can be widespread within any one area (though with probably more than one magmatic reservoir). Quaternary volcanism is also seen in the 

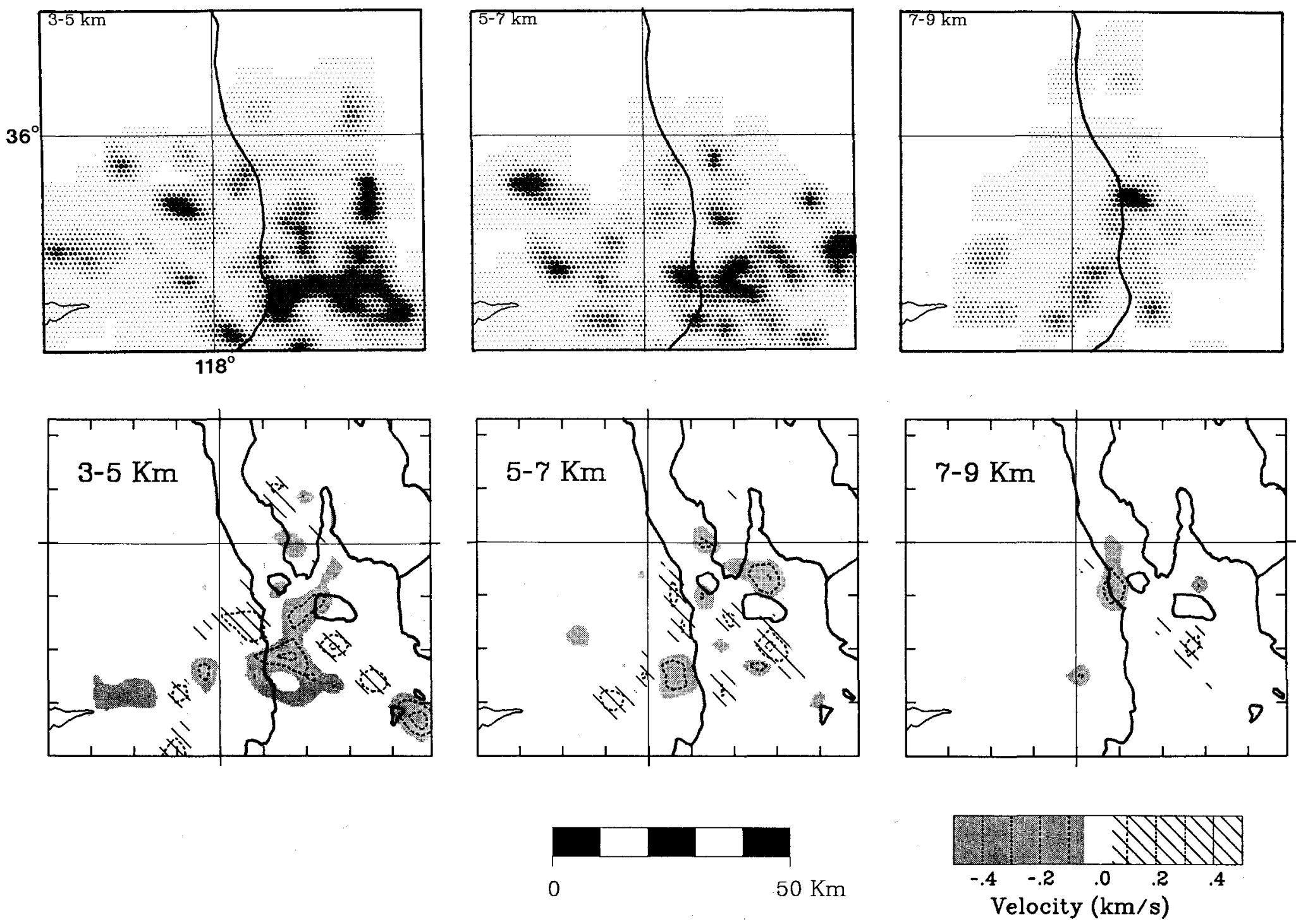

Fig. 11. Comparison of $S V$ wave attenuation (upper) and $P$ wave velocity (lower; Walck and Clayton [1987]) anomalies in three depth zones beneath the Coso-Indian Wells Valley area. Both data sets were inverted using the Coso velocity model (Table 2) for ray tracing. Note the general correlation of anomalies in the well-resolved region of the study area. The dark shaded anomalies correspond to high $S V$ wave attenuation (upper frames) or low $P$ wave velocities (lower frames). The $P$ wave velocity perturbation scale is shown in the lower right comer, and the $S V$ wave attenuation scale is shown in Figure 9. 

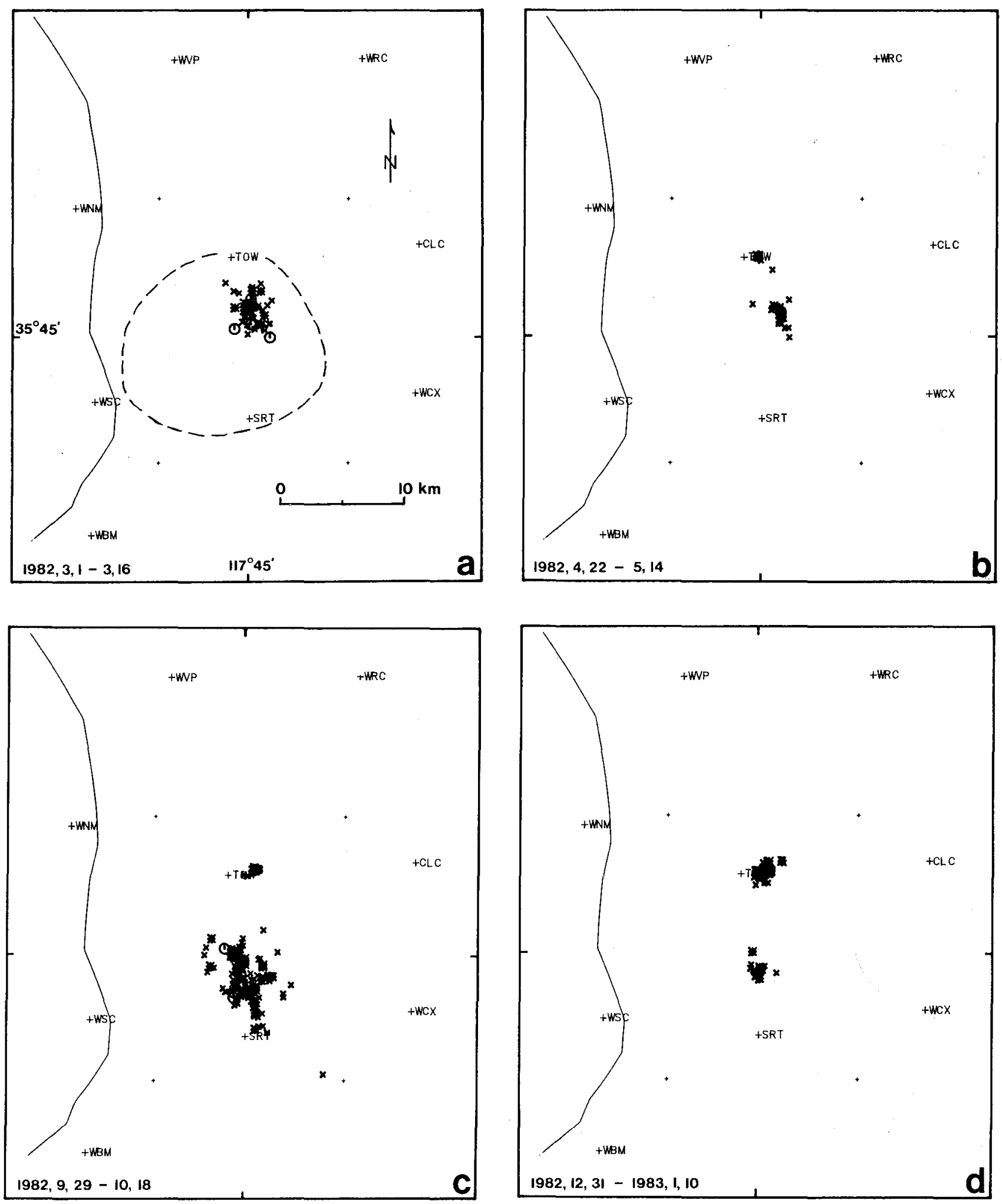

Fig. 12. Maps of CIT catalog epicenters of earthquakes which occurred in the area of the $S V$ wave attenuation anomalies (the shallowest anomaly is outlined) for the time periods indicated. The magnitude symbol scale is as follows: crosses, $M 2-3$, asterisks, $M 3-4$, circles, $M$ 4-5.

Sierra block northwest of Coso [Bacon and Duffield, 1981; Moore and Lanphere, 1983] possibly associated with extensional faulting [Jones and Dollar, 1986].

Fault displacements and earthquake focal mechanisms indicate both normal and strike-slip faulting in the Coso region (Figure 5) [Duffield et al., 1980; Roquemore, 1980; Walter and Weaver, 1980; Roquemore and Zellmer, 1986; Bent et al., 1986, Jones and Dollar, 1986]. These data indicate a local strain field 
characterized by a consistent minimum principal strain oriented horizontal and about east-west. The maximum principal strain varies from vertical to north-south horizontal. This strain field is conducive to fluid movement along north-south oriented fractures, such as the Sierran frontal fault, or along fractures between offset strike-slip fault segments.

With this information in mind, we can suggest one interpretation of the attenuation anomalies, i.e. that they are fluid concentrations associated with magmatism near the local Sierran frontal fault. These fluids could be hydrothermal or magmatic, though molten rock may be more likely. This interpretation seems reasonable given the close spatial relation of the anomalies with the frontal fault zone, the short $20-30 \mathrm{~km}$ distance between the anomalies and the Coso volcanoes, and the spatially associated earthquake swarms. Additional evidence suggesting possible magmatism beneath Indian Wells Valley includes thermal wells and anomalous ground uplift in the area directly above the shallowest anomaly [Roquemore and Zellmer, 1983; Zellmer et al., 1985]. If the magmatism were young enough and deep enough, definitive evidence of its existence at the surface of the valley may not be expected.

Other possible explanations for the anomalies cannot be ruled out. One possibility is that the shallow SV wave attenuation anomaly is related to the thick alluvial section in Indian Wells Valley. This seems unlikely, since many normal $S V$ wave seismograms are recorded at stations TOW and SRT which lie atop the center of the approximately $2-\mathrm{km}$-deep valley (Figures 2,3 , and 4). These rays travel upward through the entire extent of the valley fill, but are not abnormally attenuated. Thus, the anomalous $S V$ wave attenuation cannot be caused by travel through the sediments, but must be due to some local anomalous conditions below the sediments. Another possibility is a concentration of water in deep fractures, though this seems unlikely as well. If the deep sedimentary fill of Indian Wells Valley does not anomalously attenuate $S V$ waves, even though it is probably water-saturated for much of its extent, why then would water deeper in the crust, where its abundance is probably much less, severely attenuate $S V$ waves? Another possible attenuator is a zone of rock extensively altered by hydrothermal fluids. This may be possible, though the rheology of such rocks at depth in the crust is unknown. Also, it is curious why a similar anomaly would not be seen beneath the Coso Range where magma has been erupting for several million years, and hot artesian wells are present. Although we cannot with certainty determine the cause of the anomalous $S V$ wave attenuation, the bulk of the data suggest to us a magmatic association.

If the observed attenuation anomalies are indeed related to shallow magmatism, why would the molten rock occur beneath Indian Wells Valley and not beneath the Coso volcanic field? Geologic relations may give some insight into this question. Geologic mapping indicates that the Coso Range is a horst of fractured, granitic and metamorphic rocks (part of the composite Sierra Nevada batholith) that is mantled by the Coso volcanic rocks [Duffield et al., 1980]. These hills are structurally separated from the Sierra Nevada by normal faults. Indian Wells Valley lies just south of the Coso Range and contains about 2-21/2 km of sediments [Healy and Press, 1964]. Elder [1979] argues that the density structure of the crust has a strong effect in trapping magma at various levels. If the effective density of the crust at a given level is lower than the effective density of a magma, then the magma will not rise due to buoyancy and will pond at that level until tectonic or volatile pressure forces it to the surface. The sediments of Indian Wells Valley may be such a low-density barrier, which would effectively trap magma that has traveled up along fractures associated with the frontal fault. The fractured, relatively dense rocks that form the basement of the Coso Range, on the other hand, may provide an environment for relatively unhindered magma movement to the surface, once magma has left a deeper reservoir.

\section{CONCLUSIONS}

In this study we have used $S V$ wave seismograms of local earthquakes recorded on the local Caltech-USGS seismic array to image $S V$ wave attenuation structure in the shallow crust beneath the Coso-Indian Wells Valley region, California. Visual modeling and a tomographic back projection inversion illuminate volumes within a 20 by 30 by $10 \mathrm{~km}$ volume of the shallow crust that severely attenuate $S V$ waves passing through them. These anomalies (one shallower than $5 \mathrm{~km}$ ) lie beneath the Indian Wells Valley south of the Coso volcanic field. The anomalies generally coincide with slow $P$ wave velocity anomalies imaged by Walck and Clayton [1987]. They also coincide with the epicentral locations of earthquake swarms that occurred in 1982-1983. The shallow crust above about $5 \mathrm{~km}$ beneath the Coso geothermal area does not appear to anomalously attenuate $S V$ waves from local earthquakes. Regional and local geologic and tectonic relations suggest that the anomalies may be related to magma associated with major fractures along the eastern Sierra front.

Acknowledgments. Glenn Roquemore and John Zellmer of the Naval Weapons Center, China Lake, California provided informative discussions about and field trips into the Indian Wells Valley-Coso region. Susan Boundy provided a review and helped draft figures, Lucy Jones assisted with some data acquisition, and Christof Stork wrote the raytracing program used in the inversion. Marianne Walck and Robert Clayton discussed their $P$ wave travel time results with us. Roy Bailey provided helpful discussions and a review. This work was supported by U.S. Geological Survey contract 14-08-001-21981 and grant 14-08-001G1170. This is contribution $\mathbf{4 3 5 5}$ of the Division of Geological and Planetary Sciences, Califormia Institute of Technology.

\section{REFERENCES}

Bacon, C. R., Time-predictable bimodal volcanism in the Coso Range, California, Geology, 10, 65-69, 1982.

Bacon, C. R., and W. A. Duffield, Late Cenozoic thyolites from the Kern Plateau, southem Sierra Nevada, California, Am. J. Sci., 281, 134, 1981.

Bacon, C. R., W. A. Duffield, and K. Nakamura, Distribution of Quaternary rhyolite domes of the Coso Range, California: Implications for extent of the geothermal anomaly, J. Geophys. Res., 85(B5), 24252433, 1980

Bacon, C. R., R. Macdonald, R. L. Smith, and P. A. Baedecker, Pleistocene high-silica thyolites of the Coso volcanic field, Inyo County, California, J. Geophys. Res., 86(B11), 10223-10241, 1981.

Bailey, R. A., G. B. Dalrymple, and M. A. Lanphere, Volcanism, structure, and geochronology of Long Valley Caldera, Mono County, California, J. Geophys. Res., 81(5), 725-744, 1976.

Bent, A., C. Johnson, and H. Kanamori, Indian Wells Valley earthquake swarm: 1981-1983 (abstract), Eos Trans. AGU, 67(44), 1084, 1986.

Combs, J., Heat flow in the Coso geothemal area, Inyo County, California, J. Geophys. Res., 85(B5), 2411-2424, 1980.

Duffield, W. A., C. R. Bacon, and G. B. Dalrymple, Late Cenozoic volcanism, geochronology, and structure of the Coso Range, Inyo County, Califomia, J. Geophys. Res., 85(B5), 2381-2404, 1980.

Eichelberger, J. C., and R. Gooley, Evolution of silicic magma chambers and their relationship to basaltic volcanism, in The Earth's Crust, Geophys. Monogr. Ser., vol. 20, pp. 57-77, edited by J. G. Heacock, AGU, Washington, D. C., 1977. 
Einarsson, $\mathrm{P} ., \mathrm{S}$-wave shadows in the Krafla caldera in NE-Iceland, evidence for a magma chamber in the crust, Bull. Volcanol., 41, 1-9, 1978.

Elder, J. W., Magma traps: Part I, Theory, Pure Appl. Geophys., 117, 3-14, 1979.

Fedotov, S. A., and A. E. Faberov, On screening of transverse seismic waves and magmatic chamber in the upper mantle of the Avacha group volcanoes region (in Russian), in Volcanism and Deep Structure of the Earth, vol. 3, Nauka, Moscow, 1966.

Given, D. D., R. S. Dollar, and C. E. Johnson, An unusual sequence of swarms in Indian Wells Valley, southem California (abstract), Earthquake Notes, 54(1), 38, 1983.

Gorshkov, G. S., On the depth of the magmatic chamber of the Kliuchevskiy volcano (in Russian), Dokl. Akad. Nauk SSSR, 106(4), 703-705, 1956

Hadley, D., and H. Kanamori, Seismic structure of the Transverse Ranges, Califomia, Geol. Soc. Am. Bull., 88, 1469-1478, 1977.

Healy, J., and F. Press, Geophysical studies of basin structure along the eastem front of the Sierra Nevada, California, Geophysics, 29, 337$359,1964$.

Hill, D. P., A model for earthquake swarms, J. Geophys. Res., 82(8), 1347-1352, 1977.

Ho-Liu, P., H. Kanamori, and R. Clayton, Amplitude tomography: Theory and applications (abstract), Eos Trans. $A G U, 67(44), 1098$, 1986.

Huber, N. K., Amount and timing of late Cenozoic uplift and tilt of the central Sierra Nevada, California - Evidence from the upper San Joaquin River basin, U.S. Geol. Survey Prof. Pap., 1197, 28 pp., 1981.

Humphreys, E. D., Studies of the crust-mantle system beneath southern California, Ph.D. thesis, 189 pp., Calif. Inst. of Technol., Pasadena, 1985.

Jones, L. M., and R. S. Dollar, Evidence of Basin-and-Range extensional tectonics in the Sierra Nevada: The Durrwood Meadows swarm, Tulare County, California (1983-1984), Bull. Seismol. Soc. Am., 76(2), 439-461, 1986.

Kubota, S., and E. Berg, Evidence for magma in the Katmai volcanic range, Bull. Volcanol., 31,175-214, 1967.

Lachenbruch, A. H., and J. H. Sass, Models of an extending lithosphere and heat flow in the Basin and Range province, Geol. Soc. Am. Mem., $152,209-250,1978$.

Latter, J. H., Location of zones of anomalously high S-wave attenuation in the upper crust near Ruapehu and Ngauruhoe volcanoes, New Zealand, J. Volcanol. Geotherm. Res., 10, 125-156, 1981.

Matumoto, T., Seismic body waves observed in the vicinity of Mount Katmai, Alaska, and evidence for the existence of molten chambers, Geol. Soc. Am. Bull., 82, 2905-2920, 1971.

Moore, J. G., and M. Lanphere, Age of the Golden Trout Creek volcanic field, Sierra Nevada, California, Eos Trans. AGU, 64, 895, 1983.

Pavlis, G. L., and J. R. Booker, Progressive multiple event location (PMEL), Bull. Seismol. Soc. Am., 73, 1753-1777, 1983.
Plouff, D., and W. F. Isherwood, Aeromagnetic and gravity surveys in the Coso Range, Califomia, J. Geophys. Res., 85(B5), 2491-2501, 1980.

Reasonberg, P., W. Ellsworth, and A. Walter, Teleseismic evidence for a low-velocity body under the Coso geothermal area, J. Geophys. Res., 85(B5), 2471-2483, 1980.

Roquemore, G., Structure, tectonics, and stress field of the Coso Range, Inyo County, Califomia, J. Geophys. Res., 85(B5), 2434-2440, 1980.

Roquemore, G. R., and J. T. Zellmer, Tectonics, seismicity, and volcanism at the Naval Weapons Center, Nav. Res. Rev., 35, 3-9, 1983.

Roquemore, G. R., and J. T. Zellmer, Neotectonic development of the Coso Range, Califomia (abstract), Geol. Soc. Am. Abstr. Program, $18(2), 178,1986$

Ryall, A., and F. Ryall, Attenuation of $\mathrm{P}-$ and $S$ waves in a magma chamber in Long Valley caldera, California, Geophys. Res. Lett., 8 , $557-560,1981$.

Sanders, C. O., Location and configuration of magma bodies beneath Long Valley, California determined from anomalous earthquake signals, J. Geophys. Res., 89(B10), 8287-8302, 1984.

Sanders, C., D. Rinn, and H. Kanamori, Anomalous shear wave attenuation in the shallow crust beneath the Indian Wells Valley-Coso region, Califomia (abstract), Eos Trans. AGU, 65(45), 1009, 1984.

Shaw, H. R. The fracture mechanisms of magma transport from the mantle to the surface, in Physics of Magmatic Processes, pp. 201-264, edited by R. B. Hargraves, Princeton University Press, Princeton, N. J., 1980.

Walck, M. C., and R. W. Clayton, $P$ wave velocity variations in the Coso region, California, derived from local earthquake travel times, $J$. Geophys. Res., 92(B1), 393-406, 1987.

Walter, A. W., and C. S. Weaver, Seismicity of the Coso Range, California, J. Geophys. Res., 85(B5), 2441-2458, 1980.

Weaver, C. S., and D. P. Hill, Earthquake swarms and local crustal spreading along major strike-slip faults in Califomia, Pure Appl. Geophys., 117, 51-64, 1979.

Young, C.-Y., and R. W. Ward, Three-dimensional $Q^{-1}$ model of the Coso Hot Springs known geothermal resource area, J. Geophys. Res., 85(B5), 2459-2470, 1980.

Zellmer, J. T., C. O. Sanders, and G. R. Roquemore, Tectonic and possible volcanic interactions within Indian Wells Valley, southeastem California (abstract), Geol. Soc. Am. Abstr. Program, 17(6), 1985.

P. Ho-Liu and H. Kanamori, Seismological Laboratory, 252-21, California Institute of Technology, Pasadena, CA 91125.

D. Rinn, 809 Knollwood Terrace, Westfield, NJ 07090.

C. Sanders, U.S. Geological Survey, MS-977, 345 Middlefield Road, Menlo Park, CA 94025

(Received July 16, 1986; revised September 4, 1987; accepted October $4,1987$. ) 